\title{
Do Gun Buybacks Save Lives? Evidence from Panel Data
}

\author{
Andrew Leigh, Research School of Economics, Australian National \\ University and \\ Christine Neill, Department of Economics, Wilfrid Laurier University
}

Send correspondence to: Christine Neill, Department of Economics, Wilfrid Laurier University, Waterloo, Canada; E-mail: cneill@wlu.ca.

In 1997, Australia implemented a gun buyback program that reduced the stock of firearms by around one-fifth (and nearly halved the number of gun-owning households). Using differences across states, we test whether the reduction in firearms availability affected homicide and suicide rates. We find that the buyback led to a drop in the firearm suicide rates of almost $80 \%$, with no significant effect on nonfirearm death rates. The effect on firearm homicides is of similar magnitude but is less precise. The results are robust to a variety of specification checks and to instrumenting the state-level buyback rate. JEL (I12, K14)

\section{Introduction}

Following the 1996 massacre of thirty-five people in Port Arthur, Tasmania, the Australian federal government persuaded all states and territories to implement tough new gun control laws. Under the National Firearms Agreement (NFA), firearms legislation was tightened and made

We are grateful to Juan Baron, Philip Cook, Jean Eid, Azim Essaji, Ana Ferrer, Francisco Gonzalez, Jens Ludwig, Alex Tabarrok, Justin Wolfers, editor John Donohue, an anonymous referee, and seminar participants at the Australian National University, the Research Institute of Industrial Economics, the University of Calgary, the University of California-Berkeley, the University of Melbourne, the University of Michigan, the University of Wisconsin-Madison, and the Association for Public Policy Analysis and Management 2008 Fall Conference for valuable advice and comments on this paper, and to Jenny Chesters, Susanne Schmidt and Elena Varganova for outstanding research assistance. All errors are ours.

American Law and Economics Review

doi: 10.1093/aler/ahq013

Advance Access publication August 20, 2010

(C) The Author 2010. Published by Oxford University Press on behalf of the American Law and Economics Association. All rights reserved. For permissions, please e-mail: journals.permissions@oxfordjournals.org. 
more consistent across all states and territories. As part of the NFA, it became illegal to hold particular types of firearms, in particular certain long guns. Guns that were no longer legal were subject to a government buyback, with owners being compensated for their newly illegal firearms at market prices. ${ }^{1}$ In terms of the absolute numbers of guns destroyed, Australia's gun buyback ranks as the largest destruction of civilian firearms in any country over the period 1991-2006 (Small Arms Survey 2007, Table 2.10). Its effect was to reduce Australia's firearms stock by around one-fifth, more than 650,000 firearms. In United States terms, this would be equivalent to a reduction in the firearms stock of forty million firearms (Reuter and Mouzos 2003). Although some of the firearms that were handed in came from households with multiple firearms, survey evidence suggests that the buyback nearly halved the share of Australian households with one or more firearms. ${ }^{2}$

Previous studies of gun buybacks have typically found that they have little effect on death rates or violent crime (see, e.g., Callahan et al. 1994, who studied the 1992 buyback in Seattle, WA; and Rosenfeld, 1995, who looked at the 1991 and 1994 buybacks in St Louis, MO). Compared with these studies, an investigation of the Australian gun buyback has three major advantages. First, its scale is significantly larger than most other gun buybacks. In absolute numbers, five times as many guns were handed in under the 1997 Australian buyback as were bought back in the United Kingdom's much-touted gun buyback in the same year. Since death rate data are typically quite variable, the effects of smaller-scale buybacks are unlikely to be able to be distinguished from random noise. Second, the fact that the policy applied across the nation meant that gun owners could not simply travel across jurisdictions to purchase a replacement firearm, as can occur in the case of the more limited buybacks typical in the United

1. We use the term "buyback" here, since that is the terminology used in Australia. The program differed from what have been called buyback programs in the United States, however, where buyback programs have typically not been accompanied by a ban on the firearms "bought back."

2. We have been unable to locate reliable evidence on the share of Australian households that owned a gun in 1996, immediately prior to the buyback. The best data appear to come from the International Crime Victim Surveys (ICVS), which indicate that $15 \%$ of Australian households owned a firearm in 1992, compared with just $8 \%$ in 2000 . 
States. And third, the ability of an island nation to restrict illegal gun imports, coupled with the absence of any domestic gun manufacturers producing for the retail market, meant that legal restrictions on gun ownership were more likely to "bite" in Australia than would be the case in countries with porous land borders. ${ }^{3}$

Although researchers have studied the Australian firearms buyback, most of these studies have looked only at time series variation. This approach suffers from the problem that the control group must be inferred from past time trends. If a time-specific shock affected homicide and suicide rates at the same point as the firearms buyback, it will be impossible for time series approaches to disentangle the policy change from the shock.

By contrast, our approach in this paper exploits variation both across states and over time. The cross-state variation arises from different rates of firearm buyback in different states. Specifically, we ask the question: did firearms death rates decrease more substantially in states where more guns were bought back? To preview our results, we find that the withdrawal of 3,500 guns per 100,000 individuals reduced the firearm suicide rate by close to $80 \%$ and had no statistically significant effect on non-firearm death rates. Estimates of the effect on firearm homicides are less precise, but point estimates suggest that the firearm homicide rate also dropped by a substantial proportion. These results are robust to the inclusion of statespecific controls and time trends, to allowing for breaks in the statespecific time trends, to flexible modeling of the dynamic impact of the NFA, and to using instrumental variables techniques to allow for potential endogeneity in the state-level gun buyback rate. This paper therefore provides evidence that reduced access to firearms lowers firearm death rates and may also lower overall death by suicide and homicide.

The remainder of this paper is structured as follows. In Section 2, we briefly discuss the international evidence on firearm availability and violent deaths, as well as some of the methodological issues involved in estimating this relationship. Section 3 outlines the institutional details of the Australian firearms buyback and shows national-level trends.

3. Reuter and Mouzos (2003) raise this point and provide an extensive discussion of the background to and details of Australia's NFA, as well as a preliminary evaluation of its effects. 
Section 4 presents our cross-state empirical strategy and results. The final section concludes.

\section{Evidence on the effects of firearm availability on violent deaths}

\subsection{Firearm possession and deaths}

The relationship between firearms ownership rates and violent death rates is one of the most hotly contested issues in the economics of crime. From a theoretical standpoint, gun control could either increase or reduce violence, depending on the particular circumstances (Marceau 1998). One set of hypotheses suggests that the relationship should be positive: more guns in the hands of criminals increase the probability that an assault will end in death, while the presence of guns in a home raises the chance that a suicide attempt will be successful. But another set of hypotheses suggests a negative relationship: more guns in the hands of law-abiding citizens may have a deterrent effect, which might in turn reduce the overall incidence of violence. ${ }^{4}$ Cook and Ludwig (2006) provide a comprehensive review of the empirical literature regarding the mechanisms by which firearm ownership may affect death rates.

There are a number of studies that have found a positive relationship between firearms ownership and firearms deaths using variation across countries or across regions within a country (e.g., Killias 1993). However, it is possible that this does not reflect a causal pattern (Duggan 2001). Cultural, legislative, or socio-economic factors in particular jurisdictions could explain both high gun ownership rates and high firearm death rates.

A more compelling empirical approach is to use panel data. Under this approach, any factors that differ across jurisdictions and remain fixed over time can be controlled for by including jurisdictional-specific fixed effects in a multiple regression model. Similarly, any time-varying factors that affect all jurisdictions in the same way can be controlled for using time-specific

4. Duggan (2001) cites various estimates on the number of U.S. gun owners who successfully defend themselves from criminals each year: ranging from 75,000 to more than one million. 
fixed effects. Again, such approaches have been used at the sub-national and cross-national levels. Miller et al. (2005) find that reductions in firearm ownership rates across U.S. states are associated with declines in firearm suicide rates. Across a panel of 13 countries, Ajdacic-Gross et al. (2006) estimate a random effects model and similarly find a positive relationship between the share of firearms-owning households and the proportion of suicides committed with a gun.

While these models can control for differences in death rates that are fixed geographically or in time, without a fuller causal model of death rates, they cannot account for correlations that arise between firearm availability and death rates that are caused by a third factor. For instance, a drought may lead to both increased firearm purchases to deal with wildlife encroaching on farmland and higher suicide rates of farmers due to increased bankruptcy. Or an exogenous rise in drug trafficking could lead to increased purchases of firearms by worried householders and increased homicides due to gang-related conflict. Beyond this, many other socioeconomic variables have also been found to affect suicide and homicide, and it is quite plausible that these same factors might affect firearms purchases. ${ }^{5}$ Such factors may be unobservable to the econometrician. Moreover, there is little agreement in the literature as to an appropriate empirical model of either homicide or suicide rates, making it difficult to be sure that all relevant socio-economic factors have been addressed and therefore that estimates of the effect of firearms availability on death rates reflect a causal relationship.

Further, it may be the case that places with both high firearm ownership and high firearm death rates have relatively low homicide and suicide deaths by non-firearm methods. This suggests substitution between methods; in other words, firearms are used in homicides and suicides in places with

5. Among the factors that have been found to affect suicide rates are New Deal spending (Fishback 2007); the divorce rate (Gruber, 2004); divorce laws (Stevenson and Wolfers, 2006); the violent crime rate, the Vietnam War, and the share of the population aged 15-24 (Cebula and Zelenskaya, 2006); business cycles (Varen 2004); alcohol use (Carpenter 2004); unemployment rates and permanent income (Hamermesh and Soss 1974); and urbanization rates (Neumayer 2003). Factors correlated with homicide include inequality and poverty, percent of the population that is urban, is resident in female-headed households, or has recently moved (Cook and Ludwig 2006); and male youth unemployment rates and average weekly earnings (Narayan and Smyth 2004). 
high firearm ownership rates simply because the firearms are available. In the extreme case of complete method substitution, access to firearms has no impact on the number of violent deaths, merely the method by which those violent deaths occur. From a policy standpoint, this is clearly an important question, yet pure cross-sectional or time series methods are unable to separate out these effects.

Another concern is the accuracy of data on firearm availability. Duggan (2001) notes that a lack of reliable data on gun ownership makes many of these studies rather difficult to rely on. He uses subscriptions to gun magazines (which he shows are closely correlated with firearm ownership) as a proxy for firearm ownership. Cook and Ludwig (2006) and Bridges and Kunselman (2004) use the percentage of either suicide or accidental deaths that are due to firearms as a proxy for firearm availability. All three found that a higher (estimated) firearm availability rate was associated with higher firearm homicide rates.

Finally, the results from such studies may be contaminated by the endogeneity of firearm ownership. For example, in jurisdictions with higher rates of violent crime, individuals may be more likely to own a firearm to protect themselves. In this case, firearms ownership may merely reflect current crime rates or expectations of future crime rates. In order to identify the causal effect of access to firearms on deaths, it is preferable to exploit some exogenous source of variation in firearms ownership rates.

\subsection{Firearm regulation and deaths}

Perhaps one of the most promising avenues for identifying such exogenous changes in access to firearms is to examine the effects of changes to firearm legislation and regulations. Some caution is required in attributing changes in regulation to changes in access to firearms, since the degree of enforcement may be equally important. Indeed, it is possible that stricter legislation may not in fact reduce firearm access in the absence of enforcement. Another issue is that legislative reforms often include a package of measures - which can make it difficult to separate, for example, regulations on ownership from rules governing the proper storage of firearms. 
There have been a very large number of studies of tighter firearm legislation or other related policy changes on death rates. We cannot carry out a comprehensive review of the entire literature here. The majority of these, however, rely mostly on time series methods - including studies of the 1977 Canadian gun control legislation (Leenaars and Lester 1996; Carrington 1999) and of the 1994 U.S. federal assault weapon ban (Koper and Roth 2001a; see also Kleck 2001; Koper and Roth 2001b). These studies tend to find some evidence of a decline in firearm-related deaths following the passage of tighter gun control legislation.

Four existing papers study the effects of Australia's 1997 National Firearms Agreement on Australian firearm deaths. Chapman et al. (2006) take a purely time series approach to the question, arguing there is evidence of a decline in firearm suicides and perhaps in homicides after 1997. They also note that there were thirteen mass shootings in Australia during the period 1979-96, but none in the decade 1997-2006. Baker and McPhedran (2007) also take a simple time series approach. Their empirical findings are similar to those of Chapman et al. (2006), although their interpretation of the results is markedly different. Lee and Suardi (2010) estimate an ARIMA model and attempt to find a structural break in the time series process for firearm and non-firearm homicides and suicides at 1997 but find none.

Ozanne-Smith et al. (2004) examine the effects of firearms legislation in Australia on overall firearm deaths, using two periods of policy change. The first was a tightening of firearms legislation in the state of Victoria, which occurred around 1988, preceding by almost a decade the more general tightening of legislation that occurred in the rest of Australia in 1997. Comparing firearm deaths in Victoria and the rest of Australia, they find that such deaths fell more rapidly in Victoria during the period 1988-1995 and fell more rapidly in the rest of Australia from 1997 to 2000. They conclude that tighter gun controls led to a substantial reduction in firearmrelated deaths overall and in firearm suicides in particular. The results in that paper rely on the assumption that the NFA had no effect on firearm availability in the state of Victoria, which is not consistent with the evidence that substantially more firearms were bought back in Victoria than in many other states. 
A problem with studies of national gun control law changes that rely on time series variation is that it is impossible to distinguish between two factors, both of which may be important: (1) the effects of socio-economic or other policy changes on all suicides or homicides and (2) method substitution. ${ }^{6}$ Unless it is possible to control for all conceivable timevarying shocks, it is not feasible to control for (1) and thus identify (2).

An alternative approach is to exploit sub-national variation in firearms regulations. Since most countries regulate firearms at the national level, studies of this type have tended to use variation across jurisdictions within the United States. This has the advantage that crime statistics are more comparable, but the disadvantage that sub-national restrictions can be circumvented by buyers who are willing to travel interstate. The most studied regulatory changes have been the introduction of laws allowing concealed carry permits, shall-issue laws, and restrictions on youth firearm ownership. For example, Rosengart et al. (2007) found that the introduction of "shall-issue" laws, implemented in twenty-three states over the 1980s and 1990 s, led to an increase in the rate of firearm homicide of one per 100,000 individuals, after controlling for state-specific differences in death rates. There have also been studies of U.S. firearm buybacks (Callahan et al. 1994; Rosenfeld 1995). These typically find the buybacks have little or no effect on death rates, but the programs evaluated are much more modest than the Australian NFA.

Levitt (2004) includes changes in U.S. gun control laws over the 1990s as one of his six factors that do not explain declines in crime over the same period. He notes three reasons why gun buybacks in particular would not be expected to be effective: (1) the guns surrendered are those least likely to be used in crimes because they are surrendered voluntarily; (2) replacement guns are easily obtained; and (3) the typical buyback is relatively small in scale. We describe the NFA in the next section, but to anticipate these arguments: we argue that none of these factors are relevant to the Australian buyback; since the NFA involved a large-scale buyback of firearms, the buyback was compulsory in the sense that retaining possession of the firearms was illegal, and the guns could not be easily replaced with similar firearms.

6. For a more technical discussion of this problem, see the appendix to Neill and Leigh (2008). 


\section{a. Suicides (self-harm)}

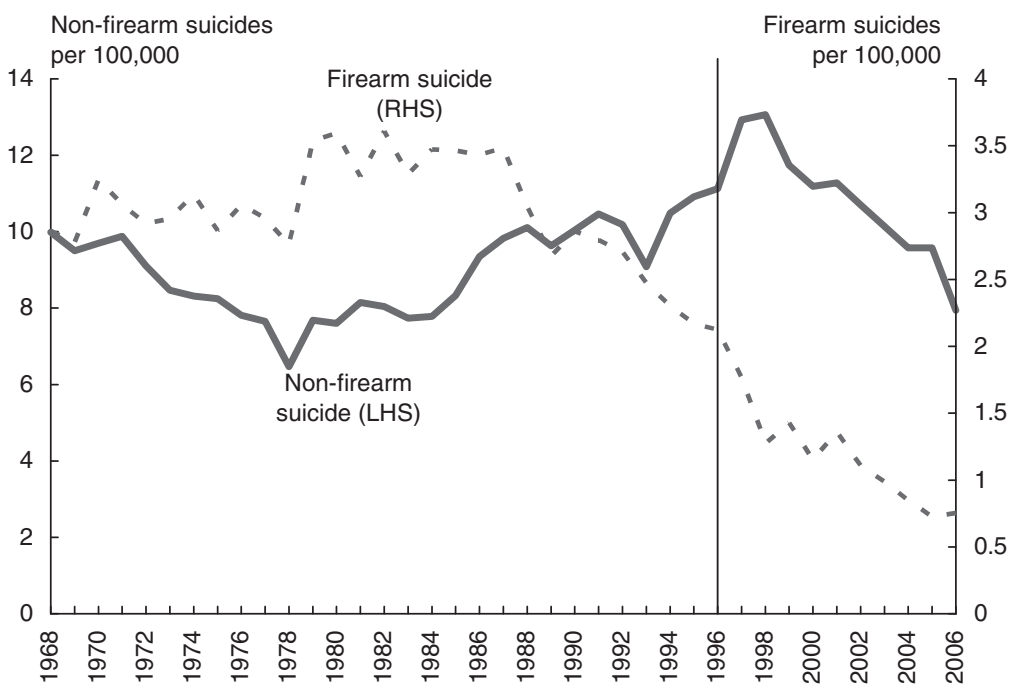

b. Homicides (assault)

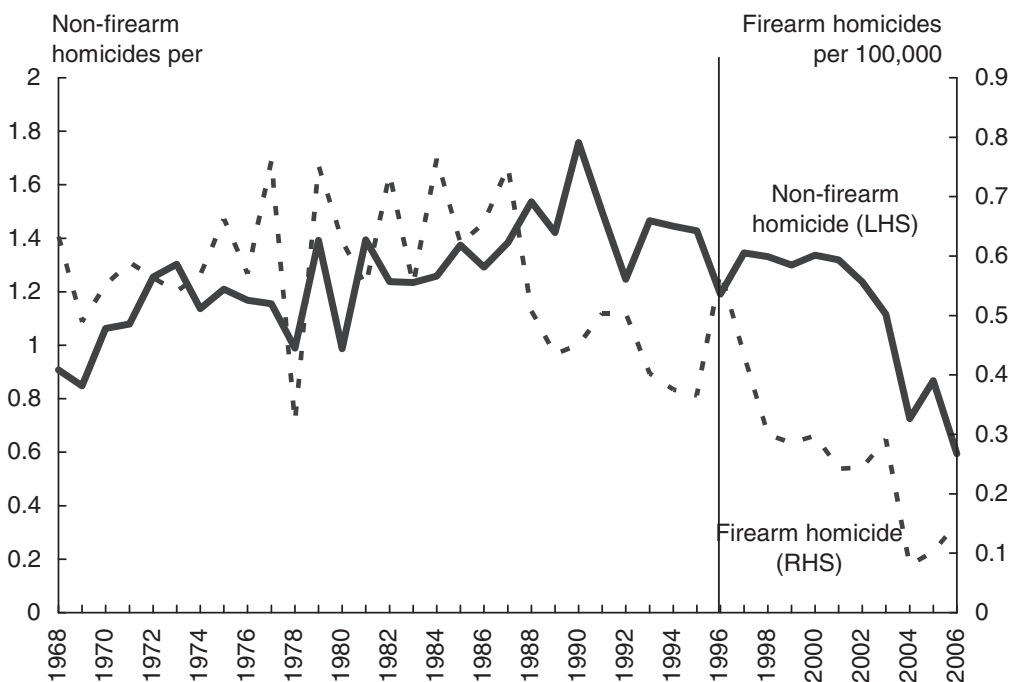

Source: Australian Bureau of Statistics, Cause of Death collection (data available on request). Data is deaths by self-harm and death by assault.

Figure 1. Firearm-Related Deaths and Non-Firearm-Related Deaths, Australia, 1968 to 2006. a. Suicides (self-harm). b. Homicides (assault). 


\section{Australian Firearm Regulation and Firearm Deaths}

\subsection{Trends in Australian Suicides and Homicides}

In the decade following the NFA, there has been a substantial drop in firearm deaths in Australia (Figures 1a and 1b). Firearm suicides have dropped from 2.2 per 100,000 people in 1995 to 0.8 per 100,000 in 2006. Firearm homicides have dropped from 0.37 per 100,000 people in 1995 to 0.15 per 100,000 people in 2006 . These are drops of $65 \%$ and $59 \%$, respectively, and among a population of 20 million individuals, represent a decline in the number of deaths by firearm suicide of about 300 and in the number of deaths by firearm homicide of about 40 per year. At the same time, the non-firearm suicide rate has fallen by $27 \%$ and the non-firearm homicide rate by $59 \%{ }^{7}$

It is also clear from Figure 1 that firearm deaths have been falling on a consistent basis in recent decades, while a similar trend is not as clear in the case of non-firearm deaths. ${ }^{8}$ Firearm deaths — both homicide and suicideare currently at exceptionally low levels by historical standards. The previous low in the rate of firearm suicide was in 1944, at 1.63 per 100,000. The firearm suicide rate has been below that level since 1998 . The firearm homicide rate is considerably more volatile, but for the years 2004 to 2007 it has been recorded as at or below 0.15 per 100,000 people. It has dipped below 0.2 per 100,000 on only one other occasion, in $1950 .{ }^{9}$

Non-firearm suicides, on the other hand, have remained relatively high compared to historical averages, despite declines in the early 2000s. The increase in non-firearm suicides from 1996 to 1998 is noteworthy, since some commentators (for instance, Baker and McPhedran 2007) have pointed to this as possible evidence of substitution from guns to other

7. There are concerns that data on external causes of death may be affected by changes to collection methods in 2002 (AIHW 2009), leading in particular to a decline in deaths categorized as self-harm (suicide) and an increase in deaths that are identified as due to external causes of undetermined intent.

8. Note again that there may be some inconsistencies in the homicide (death by assault) statistics after 2002. The figures for 2004 and 2005 seem exceptionally low and do not align with the justice statistics on homicides in those years. See Chapman et al. (2006). Recently released data from 2006 and 2007, however, do appear to be consistent with the figures from 2004 and 2005.

9. Again, however, this may reflect an inconsistency in the data. 
methods of suicide following the gun buyback. Non-firearm homicides have likewise remained relatively high compared to long-run historical averages, although they appear to have dropped sharply since 2004.

\title{
3.2. The National Firearms Agreement
}

Following the April 1996 Port Arthur killings, the Australasian Police Ministers' Council achieved agreement between federal and state governments to toughen and harmonize firearm laws across Australian states and territories. The key element of the NFA was the ban of the sale, importation, or possession of particular types of previously legal firearms - mostly automatic and semi-automatic long arms. A buyback scheme was implemented to compensate owners for the compulsory forfeiture of any newly illegal weapons. Reuter and Mouzos (2003) state that the agreement

\begin{abstract}
"effectively introduced uniform licensing and registration of firearms in all eight states and territories of Australia, replacing a patchwork that included regimes of varying stringency. Moreover, certain classes of weapons (self-loading rifles, self-loading and pump-action shotguns) were prohibited, as was the importation of these weapons. To encourage compliance with the new prohibitions, the federal government financed a large-scale gun buyback program, conducted by the states. The buyback initially covered only newly prohibited weapons, primarily long arms; later it was extended to include nonconventional weapons, such as submachine guns and heavy machine guns. There was also an amnesty for handing in unlicensed firearms during that same period, but no payments were made for these weapons" (p. 129). ${ }^{10}$
\end{abstract}

Prices were centrally determined by an expert committee, based on the retail price of the firearm, and did not vary across states. Altogether, almost 650,000 prohibited firearms were bought back during the initial amnesty. Substantial numbers of non-prohibited but unlicensed firearms were also handed in. ${ }^{11}$ Although it is difficult to be certain, due to the unreliability of survey data on gun ownership, Reuter and Mouzos (2003) state that this

10. The distinguishing feature of self-loading and pump-action weapons is that they do not require the user to insert fresh ammunition after each pull of the trigger.

11. For NSW, Australia's most populous state, Reuter and Mouzos (2003) were able to obtain data on the number of non-prohibited firearms that were handed in. In that state, 37,000 non-prohibited firearms were handed in, for no compensation. That figure was $24 \%$ of the 156,000 prohibited firearms handed in to NSW authorities. 
most likely constituted a withdrawal of around $20 \%$ of the total stock of firearms from the community.

It is extremely unlikely that this withdrawal of firearms could have been quickly reversed in Australia. There are no domestic firearms manufacturers, so that all firearms must be imported into the country. Records from the Australian Customs Service show that in the 3 years prior to 1996, Australian firearms imports averaged around 50,000 per year, of which about 25,000 were rifles. After the buyback, average imports fell to about 30,000 per year, of which 10,000 were rifles. Thus, if anything, there appears to have been a slowdown in imports after 1997. Although the available data are incomplete, it appears that law enforcement agencies were responsible for a large percentage of overall purchases. For example, one source indicates that more than one quarter of all handguns purchases in the period 1999-2002 were by law enforcement. Even if we made the extreme assumption that all imported firearms were added to the civilian firearm stock and no firearms were ever destroyed, at current import levels of 30,000 per year it would take around 20 years for the civilian firearm stock to recover to pre-buyback levels. Publicly available data on imports by state suggest there may have been a slight negative relationship between subsequent imports of firearms per capita and the buyback rate - that is, states with a high buyback rate also saw somewhat lower growth in firearm imports. This relationship is not, however, statistically significant, and we do not have information that allows us to separate out civilian purchases from law enforcement and military purchases, so we cannot be sure that this reflects primarily civilian purchases.

Although the NFA buyback targeted firearms that were of the type that had been commonly used in crimes, an important feature of the buyback is that very few of the firearms handed in to police were military-style automatic-fire weapons. For the state of Victoria (the only jurisdiction to provide a breakdown of the types of guns handed in), Reuter and Mouzos (2003) report that nearly half of the guns were .22 caliber rifles, and almost all the remainder were shotguns. Less than one in 1,000 of the weapons handed back in Victoria was an automatic. Further, given the very strict Australian legislation restricting access to hand guns, there was limited opportunity to substitute away from newly prohibited firearms towards other automatic or semi-automatic firearms. 
Table 1. Number of deaths and type of firearm used for homicides and suicides (1990-95 and 1998-2003)

\begin{tabular}{|c|c|c|c|c|c|c|}
\hline & \multicolumn{3}{|l|}{ Suicide } & \multicolumn{3}{|l|}{ Homicide } \\
\hline & Handgun & $\begin{array}{l}\text { Rifle/ } \\
\text { shotgun }\end{array}$ & $\begin{array}{l}\text { Other/ } \\
\text { unspec }\end{array}$ & Handgun & $\begin{array}{l}\text { Rifle/ } \\
\text { shotgun }\end{array}$ & $\begin{array}{l}\text { Other/ } \\
\text { unspec }\end{array}$ \\
\hline \multicolumn{7}{|l|}{ 1990-95 (A) } \\
\hline Number of deaths & 118 & 1891 & 675 & 34 & 242 & 180 \\
\hline Rate per 1 million & 1.1 & 17.9 & 6.4 & 0.3 & 2.3 & 1.7 \\
\hline$\%$ of deaths & $4.4 \%$ & $70.5 \%$ & $25.1 \%$ & $7.5 \%$ & $53.1 \%$ & $39.5 \%$ \\
\hline \multicolumn{7}{|l|}{ 1998-2003 (B) } \\
\hline Number of deaths & 153 & 998 & 242 & 64 & 112 & 131 \\
\hline Rate per 1 million & 1.3 & 8.6 & 2.1 & 0.6 & 1.0 & 1.1 \\
\hline$\%$ of deaths & $11.0 \%$ & $71.6 \%$ & $17.4 \%$ & $20.8 \%$ & $36.5 \%$ & $42.7 \%$ \\
\hline \multicolumn{7}{|l|}{ Change in deaths (B-A) } \\
\hline Change in \# of deaths & 35 & -893 & -433 & 30 & -130 & -49 \\
\hline$\%$ change in death rate & $18.1 \%$ & $-51.9 \%$ & $-67.3 \%$ & $71.5 \%$ & $-57.8 \%$ & $-33.7 \%$ \\
\hline
\end{tabular}

Source: Australian Bureau of Statistics, Cause of Death collection (data available on request).

National statistics on firearm deaths separate deaths caused by handguns from those caused by long guns. ${ }^{12}$ This is useful because the NFA applied primarily to long guns. Prior to the 1997 law change, handguns accounted for $4 \%$ of all firearm suicides and $8 \%$ of all firearm homicides (Table 1). Afterwards, the figures increased to $11 \%$ and $21 \%$, respectively, largely because of a decline in deaths attributable to long guns. ${ }^{13}$ Overall, 71\% of suicides were with identified long guns, and the same was true of $53 \%$ of homicides. Of course, not all of the long guns used in these homicides and suicides would have been subject to the buyback, but the fact that the drop in deaths was larger among the type of firearm most affected by the buyback provides suggestive evidence that the NFA played a role in the fall in firearm deaths.

The oft-heard claim that buybacks remove mostly low-risk guns (because only an individual who was not planning to use a firearm would hand it in) is typically based on U.S.-style buybacks which are

12. We were unable to obtain a reliable breakdown of firearm deaths by state by firearm type (which might otherwise have allowed us to estimate a triple-difference model).

13. Note that a tightening of handgun regulations was implemented in 2002. In general, this is thought to have been relatively ineffective compared with the 1997 NFA. However, the data do suggest that, after the 2002 law change, handgun homicides and suicides dropped more than did homicides and suicides using other firearms. 
entirely voluntary. It is more an argument about the characteristics of the owner than about the characteristics of the firearm. Such concerns have less force in the case of Australia's program, which was accompanied by a ban, than in the U.S. cases. In general, however, one might hypothesize effects in either direction. For example, if firearms owners were more likely to hand in a firearm if they had a depressed teenager in the house, the guns handed back might reasonably be described as "high risk." Conversely, if an owner's probability of handing back a firearm is negatively correlated with his or her predisposition towards violence, the guns handed back might reasonably be described as "low risk."

Because the Australian buyback was both targeted at firearms that police and the government considered high risk and that had been relatively unregulated previously, and because the buyback was accompanied by a ban and other tightening of firearm regulations, we do not think it is reasonable to describe the program as having removed primarily low-risk weapons from the Australian community. This distinguishes it from programs in the United States, where such a judgment appears more reasonable.

We have focused here on the buyback elements of the NFA. However, there were other elements of the NFA that may have led to a stronger tightening of firearm ownership legislation and enforcement in some states than in others. The most important of these were:

- that a national register of all firearms would be established (previously, not all states required registration of long guns);

- that there would be a requirement to give a valid reason for owning a firearm in order for an individual to be licensed (personal security was specifically excluded as a valid reason);

- that a permit would be required to purchase a firearm, with a required 28-day waiting period; and

- the introduction of storage and safety standards. ${ }^{14}$

To the extent that states that had initially high firearm ownership rates did so because of weaker legislation surrounding, say, sale or licensing, the NFA may have had two effects: first, to reduce the number of firearms held per capita and second to impose more stringent legislation. There is evidence that states with higher initial rates of gun ownership (including

14. A more complete description of the legal changes associated with the NFA is provided by several sources, including Reuter and Mouzos (2003). 
Tasmania and Queensland) had fewer legislative restrictions related to firearm ownership than other states (Reuter and Mouzos 2003). It is important to keep this possibility in mind when interpreting the results in this paper. Insofar as a higher buyback rate is associated with greater stringency in the overall regulatory and enforcement environment, our estimates need to be interpreted as the effect of the entire NFA policy package.

In summary, the NFA led to consistent legislation across Australian states, required licensing of gun owners and registration of guns, and significantly tightened restrictions on the types of firearms that could be legally held. In focusing on long guns, the legislation covered the group of firearms that had been most commonly used in firearm suicides and homicides and in particular outlawed firearms of the type that had been used in recent mass shootings in Australia. Internationally, the gun buyback associated with the Australian NFA was the largest of its kind in recent decades, withdrawing one fifth of the stock of firearms from the community and likely substantially reducing the number of households possessing a firearm.

\section{Empirical Strategy and Results}

\subsection{Identification issues}

While the time series evidence suggests that the NFA reduced gun deaths (Ozanne-Smith et al. 2004; Chapman et al. 2006), it suffers from the lack of a credible control group or of a fully specified model of the determinants of suicide and homicide. An alternative to developing a full predictive model of death rates is to use panel techniques, relying on variation in the intensity of the law changes associated with the NFA at the sub-national level.

Due to administrative limitations, the finest geographic level for which we are able to obtain buyback data is the state and territory. ${ }^{15}$ Australia has six states and two territories. Data on the number of firearms bought back in each jurisdiction were provided to the federal Attorney-General's department by each of these jurisdictions and are tabulated in Reuter and

15. We inquired to see whether it was possible to obtain buyback statistics for smaller geographic units, but the Attorney-General's Department (which collated statistics on the buyback) advises that such data do not exist in any systematic form. 
Table 2. Guns collected by state

\begin{tabular}{lcllc}
\hline & $\begin{array}{l}\text { Total guns } \\
\text { collected }\end{array}$ & $\begin{array}{l}\text { Guns collected } \\
\text { per 100,000 } \\
\text { residents }\end{array}$ & $\begin{array}{l}\text { Gun } \\
\text { ownership } \\
\text { rate (SE) }\end{array}$ & $\begin{array}{l}\text { Victims in } \\
\text { Port Arthur } \\
\text { massacre }\end{array}$ \\
\hline Australian Capital Territory & 5,246 & 1,698 & - & 0 \\
New South Wales & 155,774 & 2,482 & $0.134(0.009)$ & 6 \\
Northern Territory & 9,474 & 5,069 & $0.176(0.067)$ & 0 \\
Queensland & 130,893 & 3,856 & $0.213(0.016)$ & 0 \\
South Australia & 64,811 & 4,375 & $0.208(0.022)$ & 2 \\
Tasmania & 34,584 & 7,302 & $0.435(0.050)$ & 12 \\
Victoria & 207,409 & 4,512 & $0.154(0.011)$ & 12 \\
Western Australia & 51,499 & 2,869 & $0.209(0.022)$ & 1 \\
Total & 659,690 & 3,563 & $0.174(0.006)$ & 33 \\
\hline
\end{tabular}

Guns collected data are from Reuter and Mouzos (2003). Resident calculation is based on 1997 population. Gun ownership rate is the share of households with a firearm and is estimated from the 1989 and 1992 International Crime Victim Surveys. These surveys did not contain a separate designation for residents of the ACT, though Harding (1981) estimated that in the 1975-77, the gun ownership rate in the ACT was

Mouzos (2003). These data are set out in Table 2, which demonstrates that the number of guns withdrawn per 100,000 state residents differed substantially across Australian states and territories, ranging from a low of 1,698 in the Australian Capital Territory to a high of 7,302 in Tasmania.

In this paper, we ask whether firearm deaths dropped proportionately more in states where relatively more firearms were bought back. If the gun buyback itself was effective in reducing firearm-related deaths, then this would imply that states where more firearms were removed from the population should have seen a greater reduction in firearm death rates than the Australian average. Because we are comparing across states, we are able to account for time-specific shocks affecting all of Australia, something that is impossible using a simple time series approach. ${ }^{16}$

This "differences-in-differences" approach relates changes in death rates to changes in states' gun ownership rates (caused by different gun buyback rates). It assumes that all Australian states and territories would

16. This approach is similar to that taken by Ludwig and Cook (2000), in evaluating the effects of the Brady Handgun Violence Prevention Act in the United States, which required all states to implement a system of background checks and waiting periods for the purchase of handguns from licensed dealers. They ask whether death rates fell more in states that did not already meet the new federal requirements than in states that already had at least as stringent a system of checks in place and find little evidence that death rates fell as a result of the Brady Act. 
have had the same change in death rates if they had experienced the same change in firearms ownership. If states with higher initial firearm ownership rates also had weaker firearm legislation or enforcement and if the NFA led to a reduction in the relative weakness of the legislation and/or its enforcement, then any estimated effect cannot be interpreted purely as the impact of the buyback. Rather, it will be the result of both the removal of firearms and the tightening of firearms legislation and enforcement.

A second assumption in using this identification strategy is that the buyback rate in each state was exogenous, in the sense that it was not the result of preexisting trends at the state level. ${ }^{17} \mathrm{We}$ do, however, show that allowing for a national or state-level trend break beginning in 1988-the time at which the decline in firearm homicides and suicides appears to have begun - does not affect our qualitative results and that to the extent that there is any evidence that preexisting trends may bias our results, it would tend to bias our results towards the buyback having a larger impact on firearms deaths.

Implicitly, our strategy also ignores the possibility that firearms are transported across state boundaries prior to being handed in. Given that the compensation regimes were similar across Australia, we believe this is unlikely. To the extent that firearms were moved from one state to another, this will likely bias our estimates towards zero.

For the purposes of our empirical strategy, what matters is that differences in buyback rates were not correlated with other factors that might have affected gun deaths. In particular, we are concerned about two potential confounders. First, if differences in buyback rates were driven by pre-existing gun ownership rates and if the relationship between gun ownership and gun deaths is non-linear, this could lead to a spurious correlation. However, although a non-linear relationship is theoretically plausible, we have been unable to locate any studies supporting such a theory.

Second, our empirical strategy relies on the assumption that the statelevel gun buyback rate is exogenous with respect to firearms death rates. It is thus important to consider the various factors that might explain why the buyback rate varied across states. By definition, the overall buyback

17. National-level time trends are controlled by year fixed effects. We also include state-level linear time trends as a robustness check in all specifications. 
rate is equal to the rate of ownership of the newly illegal firearms multiplied by the compliance rate. To the extent that differences are driven by initial differences in firearm ownership rates, the withdrawal of firearms can be considered plausibly exogenous - driven by the initial social norms, industrial composition, and laws in each state. To test this, we estimated the relationship between two proxies of state-level gun ownership rates in 1997 and the gun buyback rate. The first proxy is data on ownership rates of all types of guns taken from the 1989 and 1992 ICVS. Since the sample size at a state level is quite small, we pool data from both waves. This is likely to be a good proxy for gun ownership when the buyback commenced, so long as gun ownership rates did not change differentially across states in the period 1989-97. The second proxy, following Cook and Ludwig (2006), is the percentage of suicides in which a firearm was used. ${ }^{18}$ Results are shown in Table 3 . As can be seen from the $R^{2}$ statistics, the correlations are very high. Over $60 \%$ of the state-level variation can be accounted for by each proxy individually, and the relationship is significant at around the $1 \%$ level. When both proxies are included in the regression, the high degree of correlation between the 1989-1992 gun ownership rate and the percentage of suicides using firearms leads to each individual relationship being insignificant, but the combined effect of the two is statistically significant at the 5\% level. These results strongly suggest that a very substantial proportion of the variation in the gun buyback rate was simply due to differences in prior gun ownership rates.

Differences in compliance rates are nonetheless likely to play some role. Combining data from several sources, Reuter and Mouzos (2003) estimate that compliance was about 50\% in Queensland and New South Wales, $70 \%$ in Victoria (the only state that previously required firearms to be registered), and $90 \%$ in Tasmania. Due to the paucity of data on firearm ownership rates prior to 1997, however, these estimates are imprecise. Differences in compliance rates would not be a concern if they were driven by factors unrelated to changes in death rates or if they were driven by factors that are controlled in our regression. For instance, farmers were more likely to be granted a license for a firearm than urban

18. We use the percentage of suicides undertaken with a firearm in 1995. Results are similar if instead we average over the years prior to the NFA. 
Table 3. Relationship between the gun buyback rate and proxies of firearm ownership

\begin{tabular}{lccc}
\hline & 1 & 2 & 3 \\
\hline Gun ownership (1989-92) & 15,241 & 7,147 & \\
$t$-statistic & $(3.51)$ & $(0.94)$ & \\
$p$-value & 0.012 & 0.391 & \\
$\%$ of suicides that are firearm & & 15,092 & 24,480 \\
$\quad t$-statistic & & $(1.27)$ & $(3.82)$ \\
$\quad p$-value & & 0.261 & 0.009 \\
Joint significance & & 7.58 & \\
$F$ & & 0.031 & \\
$p$-value & 0.6759 & 0.8073 & 0.7082 \\
$R$-squared & 8 & 8 & 8 \\
Numbers of observations & & & \\
\hline
\end{tabular}

Dependent variable is the gun buyback rate at the state level. $p$-values are in italics, $t$-statistics in parentheses. We assume that the gun ownership rate in the ACT is the same as in NSW. Estimates are cross-sectional, showing the relationship between the state-level gun buyback rate, estimated gun ownership (as described in Table 2), and the percentage of all suicides in 1995 that were identified as with a firearm at the state level.

residents, so that the less urban states would be expected to have had lower buyback rates. Since we include both state fixed effects and the percentage of the population in urban areas as controls, however, any such correlation will not bias estimates of the effect of the buyback rate on death rates. However, if the compliance rate was in part determined by factors that may also have driven differences in death rates across states, this could bias our estimates.

It is also possible that the number of guns handed back varied according to the impact of the Port Arthur massacre on each state. The most direct way in which states were affected by the massacre was if a significant number of their residents were killed. If a large number of state residents were victims of the massacre, this might have led the state's media to devote more coverage to the massacre and slanted public debate in the state in favor of the buyback. To the extent that states with more victims had higher rates of compliance with the buyback, this can be regarded as a valid source of variation (in the sense that it would only affect firearms deaths through its effect on the buyback). However, if it is also the case that a higher number of victims had a direct effect on the propensity of residents in that state to use a firearm for homicide or suicide, this would not be a valid variation (since it might affect firearms deaths directly). From the perspective of our empirical strategy, we would be 
concerned if exposure to the Port Arthur massacre affected social norms about gun use in a state, but not if it affected a state's gun buyback rate.

The data do indeed show that states with greater exposure to the Port Arthur massacre had higher buyback rates (Table 2). We observe a correlation between the number of massacre victims and the number of guns handed back per 100,000 residents of 0.5 . However, this relationship is not robust to also including the gun ownership rate in the regression. When we regress the buyback rate on both the previous gun ownership rate and the number of massacre victims, the former is positive and statistically significant, while the latter becomes insignificant, though the coefficient remains positive. As we have noted, this would be a valid source of variation, but it appears that relatively little of the cross-state variation in buyback rates was actually driven by states' "exposure" to the Port Arthur massacre.

We have been unable to find appropriate attitudinal data that would allow us to test the impact of the Port Arthur massacre on a state's social norms about gun use. However, two things can be noted about this. First, to the extent that the Port Arthur massacre affected social norms about gun use in a state, we believe that it is more likely to have affected gun homicides than gun suicides (since the event itself was a mass homicide). And second, such an impact would likely have "faded out" within a few years after the massacre. In our empirical results, we test this by separately looking at the effects of the buyback on firearm deaths in the short run and medium run.

Another possibility is that some people kept their firearms in order to defend themselves against the threat of violence in the future. If individuals were able to correctly predict trends in future crime rates (including homicide), this could lead to a negative correlation between the number of guns handed back (as a share of the population) and the future change in crime rates. To address this, we use the same information that such a "rational home defender" would have had-namely the past trend in crime rates. ${ }^{19}$ If this defensive gun-use hypothesis is valid, we

19. The assumption that the general public forecasts future crime rates by using past trends seems reasonable to us, though we know of no empirical evidence on this point. In the U.S. context, Levitt (2004) shows that even experts appear to predict future crime rates through linear projection. 
would expect to see our results disappear when we control for state-specific time trends.

Finally, it is possible that buyback rates varied across states due to differences in enforcement of the new legislation across states. For instance, the state police forces may have been more active in encouraging firearm owners to hand in their newly illegal weapons in some states than in others. However, it seems improbable that this type of variation would be related to expectations of future changes in death rates. Indeed, to the extent that any relationship existed, state authorities who anticipated a rise in gun deaths would probably have enforced the legislation more strictly. This would bias the results towards finding that a higher buyback rate led to higher death rates.

\subsection{Main Results}

We begin by plotting the change in the number of guns (per 100,000 people) against the change in homicide and the change in suicide, in each case comparing the period 1990-95 with the period 1998-2003. Note that this comparison drops 1996 (the year in which the Port Arthur massacre took place), as well as 1997 (the year during which the buyback occurred). It also omits the most recent years in which firearm death rates have been very low. Figure 2 shows graphically the results from this exercise. For both gun homicide and gun suicide, we observe a negative relationship between the death rate and the buyback rate. A similar relationship is not visible in the case of non-firearm deaths.

More formally, these results can be shown in the stripped-down regression model:

$$
\Delta D_{s}=\alpha+\beta \Delta G_{S}+\varepsilon_{s}
$$

where $s$ indexes states, $\Delta D$ is the change in the gun death rate, $\Delta G$ is the change in the gun ownership rate, and $\varepsilon$ is an IID error term. Econometrically, this differenced specification is similar to a model with state and year fixed effects. ${ }^{20}$

20. This model is one of the two recommended by Bertrand et al. (2004) to deal with serial correlation in a differences-in-differences model. The other key method they suggest is to use a full panel model but to cluster the standard errors at the jurisdictional level to allow for unspecified forms of serial correlation, which we estimate as Equation (2). 
530 American Law and Economics Review V12 N2 2010 (509-557)

\section{a. Firearm suicides}

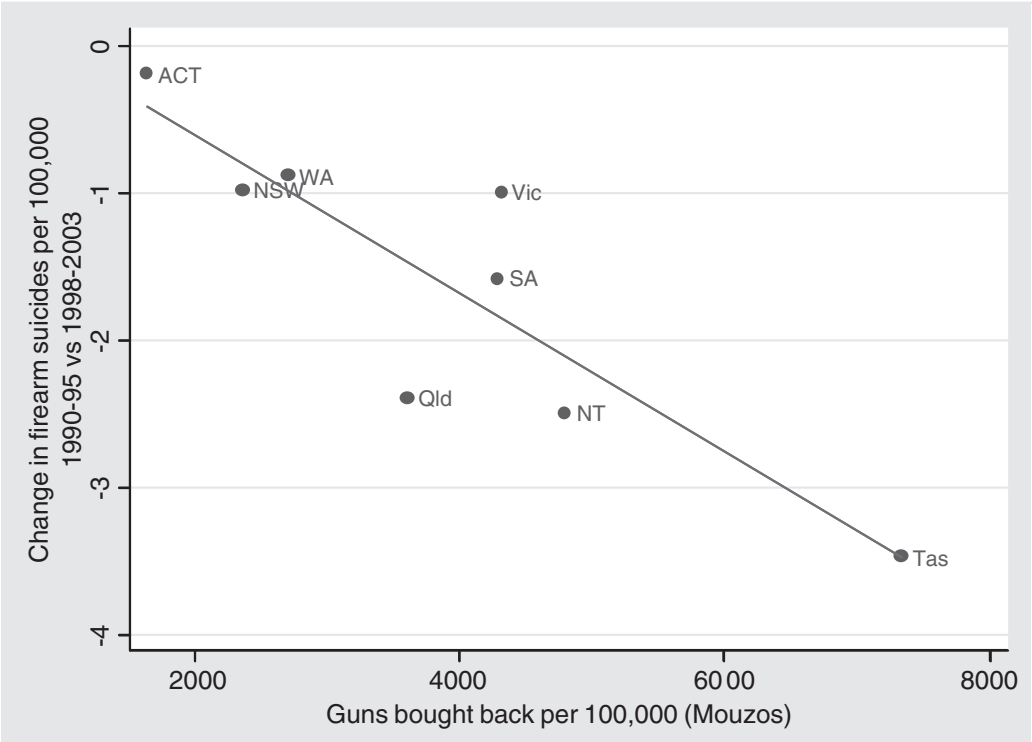

b. Firearm homicides

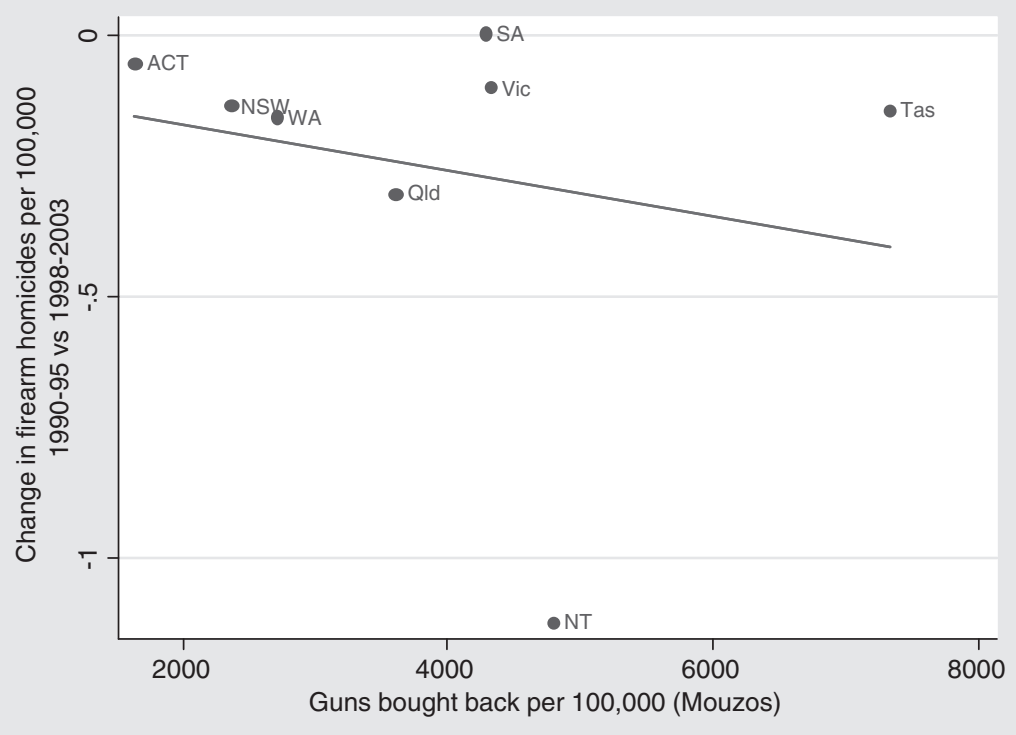


Figure 2. (continued).

\section{Non-firearm suicides}

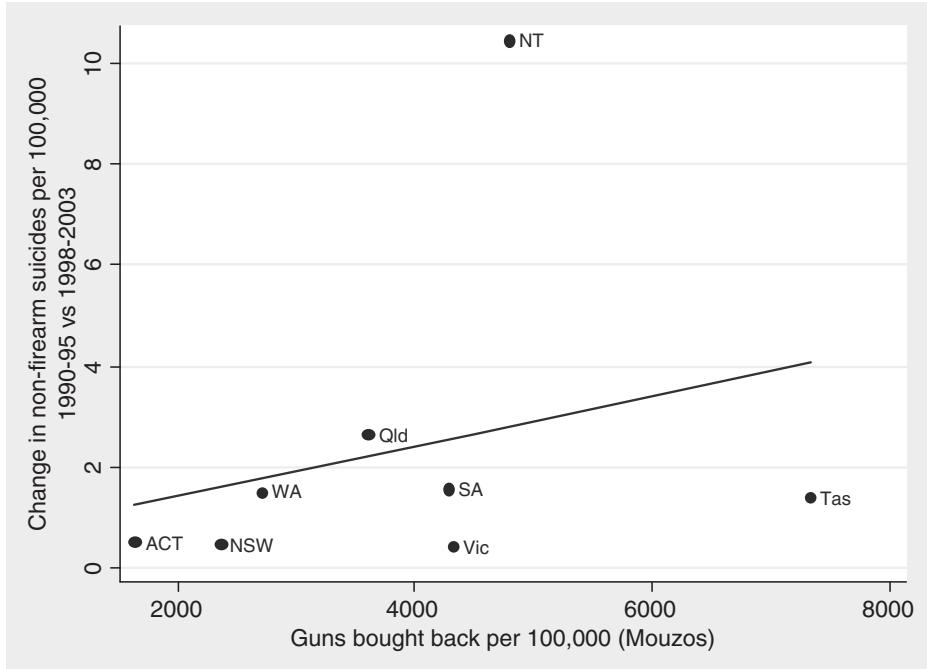

\section{d. Non-firearm homicides}

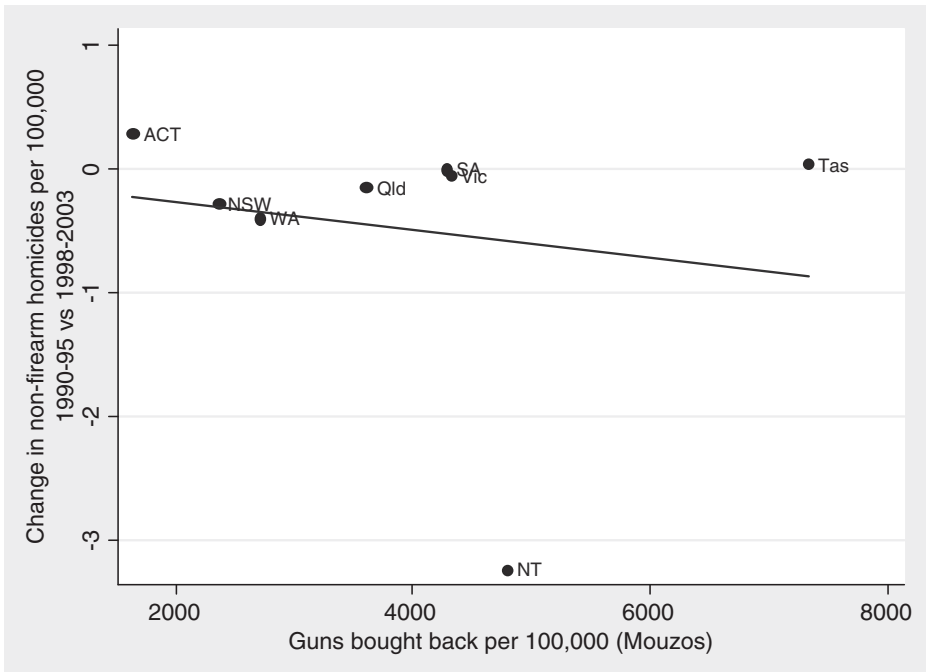

Source: Australian Bureau of Statistics, Cause of Death collection (data available on request).

Figure 2. State-Level Percentage Point Change in Average Firearm Suicide and Homicide Rate from 1990-95 to 1998-2003 Relative to Gun Buyback Rate. a. Firearm Suicides. b. Firearm Homicides. c. Non-Firearm Suicides. d. Non-Firearm Homicides. 
Table 4. Estimated effect of the gun buyback rate on death rates: 'stripped down' method (difference between averages for 1990-95 and 1998-2003). Guns coefficient represent the impact of buying back 1000 firearms

\begin{tabular}{|c|c|c|c|}
\hline & $\begin{array}{l}\text { Firearm } \\
\text { suicide }\end{array}$ & $\begin{array}{l}\text { Non-firearm } \\
\text { suicide }\end{array}$ & $\begin{array}{c}\text { All } \\
\text { suicides }\end{array}$ \\
\hline Guns bought back & $-0.537^{* * *}$ & 0.497 & -0.041 \\
\hline$t$-statistic & $(4.46)$ & $(0.66)$ & $(0.06)$ \\
\hline$p$-value & 0.004 & 0.532 & 0.956 \\
\hline$R^{2}$ & 0.7685 & 0.0683 & 0.0006 \\
\hline Number of observations & 8 & 8 & 8 \\
\hline 1990-1995 average death rate & 2.55 & 10.2 & 12.7 \\
\hline Implied change in death rate & -1.9 & 1.7 & -0.1 \\
\hline Implied $\%$ change in deaths & $-74 \%$ & $17 \%$ & $-1 \%$ \\
\hline Lower limit of $95 \%$ CI for death rate & -2.9 & -4.7 & -6.2 \\
\hline Upper limit of $95 \%$ CI for death rate & -0.8 & 8.2 & 5.9 \\
\hline $\begin{array}{l}\text { Implied change in number of deaths } \\
\text { (at } 2005 \text { population) }\end{array}$ & -376 & 348 & -28 \\
\hline Lower limit of $95 \%$ CI for death rate & -582 & -935 & $-1,230$ \\
\hline \multirow[t]{2}{*}{ Upper limit of $95 \% \mathrm{CI}$ for death rate } & -170 & 1,631 & 1,173 \\
\hline & $\begin{array}{c}\text { Firearm } \\
\text { homicide }\end{array}$ & $\begin{array}{l}\text { Non-firearm } \\
\text { homicide }\end{array}$ & $\begin{array}{c}\text { All } \\
\text { homicides }\end{array}$ \\
\hline Guns bought back & -0.044 & -0.115 & -0.160 \\
\hline$t$-statistic & $(0.54)$ & $(0.45)$ & $(0.47)$ \\
\hline$p$-value & 0.608 & 0.671 & 0.654 \\
\hline$R^{2}$ & 0.0464 & 0.0322 & 0.0358 \\
\hline Number of observations & 8 & 8 & 8 \\
\hline 1990-1995 average death rate & 0.43 & 1.47 & 1.91 \\
\hline Implied change in death rate & -0.16 & -0.40 & -0.41 \\
\hline $\begin{array}{l}\text { Implied \% change in death rate of } \\
\text { Australian buyback }\end{array}$ & $-36 \%$ & $-27 \%$ & $-22 \%$ \\
\hline Lower limit of $95 \%$ CI for death rate & -0.9 & -2.6 & -3.5 \\
\hline Upper limit of $95 \%$ CI for death rate & 0.5 & 1.8 & 2.3 \\
\hline $\begin{array}{l}\text { Implied change in number of deaths } \\
\text { (at } 2005 \text { population) }\end{array}$ & -31 & -81 & -82 \\
\hline Lower limit of $95 \% \mathrm{CI}$ for death rate & -172 & -522 & -691 \\
\hline Upper limit of $95 \% \mathrm{CI}$ for death rate & 110 & 361 & 468 \\
\hline
\end{tabular}

Dependent variable is the identified death rate, in deaths per million people. Gun buyback rate is measured as guns per thousand people. Robust $t$-statistics in parentheses. Estimates are from Equation (1), using a single differenced observation per state for a total of eight observations. Differences are calculated as differences in average death rates between the periods 1990-1995 and 1998-2003.

* significant at $10 \%$.

** significant at $5 \%$.

$* * *$ significant at $1 \%$ level.

The results are shown in Table 4. The effect of the buyback on firearm suicides is clear. Withdrawing 3,500 guns per 100,000 individuals (approximately the rate of withdrawal due to the NFA) is estimated to 
reduce firearm suicides by 1.9 per 100,000 . This represents a $74 \%$ decline from the 1990-95 average of 2.55, or 376 fewer deaths per year given Australia's population of around 20 million. The $95 \%$ confidence interval on the firearm suicide rate ranges from -0.8 deaths per 100,000 (a 33\% fall compared with the 1990-95 average death rate) to -2.9 deaths per 100,000 , a figure that is larger than the average firearm suicide rate during 1990-95. The point estimate on firearm homicides is negative and large relative to the actual rate of firearm homicidesimplying a decrease in firearm homicides of $36 \%$. The results on firearm homicide and suicide highlight a difficulty with this estimation method. The variability in the data means that the confidence intervals built around estimates based on the level of the death rate often extend so far that they could not exclude a drop in death rates greater than the initial death rate. $^{21}$ We deal with this concern later in the paper by using a Tobit model (Section 4.1.4).

The point estimates for non-firearm suicides and homicides are smaller in magnitude relative to their associated death rates and have larger standard errors. They are also smaller relative to the pre-existing death rates. Because there are so many more non-firearm suicides (and homicides) than firearm deaths, we cannot reject the possibility that there was $100 \%$ method substitution - i.e. that any reduction in firearm deaths was accompanied by an increase in deaths by other methods. This is unfortunate from a statistical perspective but is the inevitable result of the fortunate fact that Australia already had relatively few firearm deaths relative to non-firearm deaths. However our panel specification-in Section 4.1.2 - suggests that the time path of non-firearms deaths makes it improbable that $100 \%$ method substitution occurred.

While the differenced specification is one approach for dealing with differences-in-differences models with serial correlation, it does have some important disadvantages. In particular, it does not provide a natural way for dealing with the possibility that pre-existing trends in firearm deaths were correlated with gun buyback rates. Nor does it allow us to examine the dynamics of the process or to introduce other socioeconomic variables that vary at the state-year level. For these reasons,

21. This is not surprising given that the model has only eight observations and six degrees of freedom. 
we also consider the model in a levels specification - that is, we use a dataset containing annual data on death rates from each state from 1968 to 2006 , so that the total number of observations is now eight states/ territories by 39 years $=312$. In this case, the policy change variable (guns bought back) takes a zero value for all years prior to 1996 and for 1997 and later takes a constant value for each state equal to the buyback rate for that state. This variable can be considered in the same light as a typical policy change variable in a differences-in-differences study except that the state-level variation comes not from differences in the timing of the policy change, but rather from differences in its magnitude. Although our main specification includes 1996 and 1997, we show below that most results are robust to dropping the victims of the Port Arthur massacre and/or 1997 firearms deaths.

The regression here, then, is:

$$
D_{s t}=\alpha+\beta \Delta G_{s} \operatorname{post} 97_{t}+S_{S} \sigma+S_{s}+Y_{t} \tau+\mu_{s t}
$$

where $\Delta G_{s}$ post $97_{t}$ is the number of guns bought back per 100,000 population in the state, $S_{s}$ is a full set of state fixed effects, $Y_{t}$ is a full set of year fixed effects, and $\mu$ is an IID error term. We include a vector of socio-economic variables in some specifications, including the unemployment rate, the percentage of the population that is living in an urban area, the proportion aged 20-24, and the share aged over $65 .^{22}$ Unfortunately, much of these data (although not the unemployment rate) are reliably available only for Census years - we use a simple linear interpolation to estimate data between years where necessary. All standard errors are clustered at the state level. Note that there are disadvantages to using clustered standard errors in a model with only eight clusters. Bertrand et al. (2004) note in particular the weak power

22. We also examined models including controls for the prisoners and police per capita in any given state/year. There is an extensive literature regarding concerns on inference in reduced form models that include these types of variables, due to likely endogeneity (e.g., Levitt, 2004). We also included controls for the number of men aged 15-19 and 20-24. Including these controls did not change our main estimates but did reduce the number of state-year combinations we could include in our regressions, due to missing observations in some cases. Including information on the percentage of the population that is indigenous also had little effect on our main estimates, but reliable data were only available after 1991. Full results are reported in Leigh and Neill (2010). 
of such tests to correctly reject the null when there is in fact a true effect. In the presence of substantial serial correlation and few clusters, it is also likely that actual rejection rates will remain higher than the asymptotic level of the test. (In simulations with Current Population Survey data, Bertrand, Duflo, and Mullainathan look at how often a clustered model rejects the null at the $5 \%$ level. With fifty states, they observe a $6 \%$ rejection rate, and with ten states, they observe an $8 \%$ rejection rate.)

Table 5 shows the results of these regressions. For each of the six key outcome variables, four regressions are shown. All regressions incorporate state and year fixed effects. The second column adds state-specific time trends, the third adds in the socio-economic variables, and the fourth includes both of these. The results are fairly consistent across these specifications and in line with the results in Table 4. Introducing the socio-economic variables has little effect on the magnitude of the coefficients for firearm suicide or homicide, and typically they are not either individually or jointly statistically significant in the regressions. This may reflect the fact that demographics change quite slowly over time, combined with our reliance on interpolations, making it difficult to separate them out from the Australia-wide year fixed effects. We would not want to conclude from this that socio-economic factors do not affect homicide or suicide rates, since our empirical strategy likely soaks up much of the effects of these factors in either the state or year fixed effects.

The estimates show very consistently a marked relative decline in firearm suicides in states with higher buyback rates after 1997. The point estimates are slightly smaller than those in Table 4 and suggest that a buyback of 3,500 guns per 100,000 individuals (the size of the 1997 buyback) in one state would reduce firearm suicide rates by between 1.1 and 2.0 deaths per 100,000 relative to a state with no reduction in firearms; that is between $45 \%$ and $78 \%$ compared with the average firearm suicide rate in 1990-1995 of 2.55 per 100,000 . The $95 \%$ confidence interval in all specifications suggests a minimum decline in firearm suicides of $18 \%$ compared with the average firearm suicide rate in 1990-1995.

The estimates on firearm homicides are less consistent, likely because of the greater volatility in firearm homicides. Most of the point estimates suggest that a buyback of 3,500 guns per 100,000 individuals would reduce death rates to below zero, beginning from a baseline equal to the 
Table 5. Estimated effects of the gun buyback rate on death rates (1968 to 2006). Guns coefficients represent the impact of buying back 1,000 firearms

\begin{tabular}{|c|c|c|c|c|c|c|c|c|c|c|c|c|}
\hline \multirow[b]{2}{*}{ Suicide } & \multicolumn{4}{|l|}{ Firearm } & \multicolumn{4}{|c|}{ Non-firearm } & \multicolumn{4}{|l|}{ Total } \\
\hline & & \multirow{6}{*}{$\begin{array}{c}-.0 .569^{* * *} \\
(6.39)\end{array}$} & & & \multirow{6}{*}{$\begin{array}{c}0.796 \\
(1.20)\end{array}$} & \multirow{6}{*}{$\begin{array}{l}0.528 \\
(0.97)\end{array}$} & & & \multirow{6}{*}{$\begin{array}{c}0.469 \\
(0.76)\end{array}$} & \multirow{6}{*}{$\begin{array}{r}-0.041 \\
(0.07)\end{array}$} & \multirow{3}{*}{$\begin{array}{c}0.266 \\
(0.67) \\
0.655 \\
(0.33)\end{array}$} & \multirow{3}{*}{$\begin{array}{r}-0.383 \\
(0.88) \\
-0.3286 \\
(1.49)\end{array}$} \\
\hline Guns bought back & \multirow[t]{5}{*}{$\begin{array}{c}-0.327^{* * *} \\
(5.17)\end{array}$} & & $\begin{array}{c}-0.424^{* * *} \\
(6.83)\end{array}$ & $\begin{array}{c}-0.494^{* *} \\
(3.20)\end{array}$ & & & $\begin{array}{c}0.691 \\
(1.71)\end{array}$ & $\begin{array}{l}0.112 \\
(0.35)\end{array}$ & & & & \\
\hline Unemployment rate & & & $\begin{array}{l}0.207 \\
0.18\end{array}$ & $\begin{array}{r}-0.169 \\
(0.19)\end{array}$ & & & $\begin{array}{l}0.447 \\
(0.15)\end{array}$ & $\begin{array}{r}-3.117 \\
(1.30)\end{array}$ & & & & \\
\hline$\%$ of pop urban & & & $\begin{array}{r}-0.502 \\
(0.74)\end{array}$ & $\begin{array}{r}-1.533 \\
(1.72)\end{array}$ & & & $\begin{array}{c}6.353 \\
(1.73)\end{array}$ & $\begin{array}{l}2.102 \\
(1.35)\end{array}$ & & & $\begin{array}{c}5.851^{*} \\
(1.91)\end{array}$ & $\begin{array}{c}0.569 \\
(0.49)\end{array}$ \\
\hline$\%$ of pop $20-24$ yo & & & $\begin{array}{r}-3.900^{*} \\
(2.06)\end{array}$ & $\begin{array}{r}-6.32^{*} \\
(1.93)\end{array}$ & & & $\begin{array}{r}-3.142 \\
(0.57)\end{array}$ & $\begin{array}{r}12.689^{*} \\
(2.10)\end{array}$ & & & $\begin{array}{r}-7.042 \\
(1.16)\end{array}$ & $\begin{array}{l}6.365 \\
(0.99)\end{array}$ \\
\hline$\%$ of pop $>65$ yo & & & $\begin{array}{l}3.141 \\
(1.37)\end{array}$ & $\begin{array}{r}-0.954 \\
(0.19)\end{array}$ & & & $\begin{array}{r}-8.113 \\
(0.89)\end{array}$ & $\begin{array}{c}16.988 \\
(1.11)\end{array}$ & & & $\begin{array}{r}-4.972 \\
(0.67)\end{array}$ & $\begin{array}{r}16.034 \\
(0.89)\end{array}$ \\
\hline$R^{2}$ & 0.731 & 0.7476 & 0.7749 & 0.7934 & 0.4968 & 0.6915 & 0.5645 & 0.737 & 0.4032 & 0.5896 & 0.4908 & 0.6331 \\
\hline \multicolumn{13}{|l|}{ Homicide } \\
\hline Guns bought back & $\begin{array}{c}-0.100 \\
(1.57)\end{array}$ & $\begin{array}{c}-0.200^{* * *} \\
(4.13)\end{array}$ & $\begin{array}{c}-0.138^{* *} \\
(2.49)\end{array}$ & $\begin{array}{r}-0.184^{*} \\
(1.90)\end{array}$ & $\begin{array}{r}-0.150 \\
(0.54)\end{array}$ & $\begin{array}{r}-0.101 \\
(0.39)\end{array}$ & $\begin{array}{r}-0.129 \\
(0.68)\end{array}$ & $\begin{array}{r}-0.079 \\
(0.48)\end{array}$ & $\begin{array}{r}-0.250 \\
(0.74)\end{array}$ & $\begin{array}{r}-0.301 \\
(1.11)\end{array}$ & $\begin{array}{r}-0.266 \\
(1.15)\end{array}$ & $\begin{array}{r}-0.264^{* *} \\
(2.88)\end{array}$ \\
\hline Unemployment rate & & & -0.677 & -0.489 & & & $-1.841^{*}$ & -0.402 & & & $-2.518^{*}$ & -0.892 \\
\hline
\end{tabular}


Table 5. (Continued)

\begin{tabular}{|c|c|c|c|c|c|c|c|c|c|c|c|c|}
\hline & \multicolumn{4}{|l|}{ Firearm } & \multicolumn{4}{|c|}{ Non-firearm } & \multicolumn{4}{|l|}{ Total } \\
\hline & & & $(1.26)$ & $(1.04)$ & & & $(2.08)$ & $(0.81)$ & & & $(2.06)$ & $(1.14)$ \\
\hline$\%$ of pop urban & & & $\begin{array}{r}-1.196 \\
(1.56)\end{array}$ & $\begin{array}{r}-0.645 \\
(1.75)\end{array}$ & & & $\begin{array}{r}-2.068 \\
(1.75)\end{array}$ & $\begin{array}{r}1.844^{* *} \\
(3.18)\end{array}$ & & & $\begin{array}{r}-3.264 \\
(1.71)\end{array}$ & $\begin{array}{r}0.166^{* * *} \\
(4.10)\end{array}$ \\
\hline$\%$ of pop $20-24$ yo & & & $\begin{array}{r}-2.932^{*} \\
(2.17)\end{array}$ & $\begin{array}{r}-5.36^{* *} \\
(3.01)\end{array}$ & & & $\begin{array}{r}-1.813 \\
(0.71)\end{array}$ & $\begin{array}{r}-3.757 \\
(0.91)\end{array}$ & & & $\begin{array}{r}-4.745 \\
(1.47)\end{array}$ & $\begin{array}{r}-9.122 \\
(1.60)\end{array}$ \\
\hline$\%$ of pop $>65$ yo & & & $\begin{array}{l}2.758 \\
(1.51)\end{array}$ & $\begin{array}{r}-2.479 \\
(1.08)\end{array}$ & & & $\begin{array}{c}6.777 \\
(1.45)\end{array}$ & $\begin{array}{c}2.268 \\
(0.92)\end{array}$ & & & $\begin{array}{c}9.535 \\
(1.51)\end{array}$ & $\begin{array}{r}-0.212 \\
(0.05)\end{array}$ \\
\hline$R^{2}$ & 0.4028 & 0.4382 & 0.4287 & 0.4973 & 0.8159 & 0.8415 & 0.8102 & 0.84 & 0.833 & 08649 & 0.8423 & 0.8919 \\
\hline Year Fixed Effects & $\mathrm{y}$ & $\mathrm{y}$ & $\mathrm{y}$ & $\mathrm{y}$ & $\mathrm{y}$ & $\mathrm{y}$ & $\mathrm{y}$ & $\mathrm{y}$ & $\mathrm{y}$ & $\mathrm{y}$ & $\mathrm{y}$ & $\mathrm{y}$ \\
\hline State Fixed Effects & $\mathrm{y}$ & $\mathrm{y}$ & $\mathrm{y}$ & $\mathrm{y}$ & $\mathrm{y}$ & $\mathrm{y}$ & $\mathrm{y}$ & $\mathrm{y}$ & $\mathrm{y}$ & $\mathrm{y}$ & $\mathrm{y}$ & $\mathrm{y}$ \\
\hline State-specific Time Trends & & $\mathrm{y}$ & & $\mathrm{y}$ & & $\mathrm{y}$ & & $\mathrm{y}$ & & $\mathrm{y}$ & & $\mathrm{y}$ \\
\hline Socio-economic controls & & & $\mathrm{y}$ & $\mathrm{y}$ & & & $\mathrm{y}$ & $\mathrm{y}$ & & & $\mathrm{y}$ & $\mathrm{y}$ \\
\hline Number of observations & 312 & 312 & 275 & 275 & 312 & 312 & 275 & 275 & 312 & 312 & 275 & 275 \\
\hline
\end{tabular}

Dependent variable is the identified death rate, in deaths per million people. Gun buyback rate is measured as guns per thousand people. Estimates from a panel model, with annual observations at the state level. Observations: 312, except for those using socio-economic controls which have 275. Robust $t$-statistics in parentheses.

* significant at $10 \%$.

** significant at $5 \%$.

*** significant at $1 \%$ level. 
Table 6. Estimated correlation between the gun buyback rate and trends in death rates prior to the buyback (1968 to 1995)

\begin{tabular}{lcllcc}
\hline Firearm suicide & $\begin{array}{l}\text { Firearm } \\
\text { homicide }\end{array}$ & $\begin{array}{l}\text { Non-firearm } \\
\text { suicide }\end{array}$ & $\begin{array}{l}\text { Non-firearm } \\
\text { homicide }\end{array}$ & Suicide & Homicide \\
\hline Guns bought back* year & $0.0184 * *$ & -0.0019 & 0.0019 & -0.0039 & -0.0059 \\
$t$-statistic & $(2.68)$ & $(1.14)$ & $(0.17)$ & $(0.84)$ & $(1.17)$ \\
$R^{2}$ & 0.6759 & 0.5227 & 0.6167 & 0.8515 & 0.8865 \\
Number of observations & 224 & 224 & 224 & 224 & 224 \\
\hline
\end{tabular}

Dependent variable is the identified death rate, in deaths per million people. Gun buyback rate is measured as guns per thousand people. Estimates from a panel model, with annual observations at the state level. Sample only includes years prior to the NFA (i.e. 1995 and earlier) in order to isolate relationship between trends in death rates prior to the NFA and the state-level magnitude of the buyback rate. Robust $t$-statistics in parentheses.

* significant at $10 \%$.

$* *$ significant at $5 \%$.

*** significant at $1 \%$ level.

average firearm homicide rate between 1990 and 1995. This is in part due to the inclusion of the deaths from the Port Arthur incident in 1996 in the model. We show in Section 4.1.3 that if we introduce a dummy variable equal to 1 in Tasmania in 1996 and zero elsewhere that the estimated coefficients fall to more closely resemble the result in Table 4.

Once again, the estimates show no evidence that higher buyback rates were associated with any statistically significant difference in non-firearm homicide or suicide rates. Point estimates on non-firearm suicide rates are larger than those in Table 4, largely due to the inclusion of years after 2003 in the analysis (see Section 4.1.2).

\subsection{Robustness checks}

4.1.1. Controlling for state-specific trends in death rates. The introduction of state-specific time trends appears to increase the magnitude of the estimated effects of the gun buyback on firearm death rates (Table 5). ${ }^{23}$ This suggests that guns were actually returned at a lower rate in states where firearm deaths had been falling more rapidly. We check this result by estimating the correlation between the firearm buyback rate and trends in death rates prior to 1997 (Table 6). The results show that firearm suicide rates had been increasing faster in states with high firearm buyback rates prior to 1995

23. All results here allow for linear trends, but models with quadratic trends yield similar results. 
but that the buyback rate had no effect on the growth rates of other types of deaths. This is not consistent with the notion that different compliance rates were the result of either a self-defense motivation or a desire to retain firearms in order to carry out already established suicide plans. If anything, more guns were handed back in states where firearm suicides and homicides had been falling at a slower rate.

Table 7 shows the effect of including a state-specific linear year trend and allowing for a break in that trend in 1988, around the time when firearm suicide and homicide rates appear to have begun to decline nationwide. Consistent with the evidence in Table 6, this does little to change the qualitative results. Indeed, if anything, the relationship between the buyback rate and firearm death rates becomes stronger, particularly in the case of firearm homicides. Similar results obtain if, instead of allowing for a break in trend in 1988, the model is estimated on data from 1988 onwards (see Leigh and Neill 2010). These results are not sensitive to moving the year in which the trend break is estimated to occur forward or backward by several years. The results reported here are clearly, then, not an artifact of the decline in deaths evident in the nationallevel data beginning in the late 1980s.

4.1.2. Allowing for dynamics in the impact of the policy change. While it has become common to include state-specific time trends to account for the possibility of either serial correlation or policy endogeneity in policy quasi-experiment studies, Wolfers (2006) argues that this may lead to biased estimates of the policy change in the event that there are important dynamics in the influence of a policy on outcomes. In this case, we might expect that the effects of the differences in gun buyback rates across states might fade out over time as cross-state movements or subsequent firearm purchases mitigated the initial effects of the buyback. In that case, the estimates in Table 5 would underestimate the short-run impact of the buyback on cross-state differences in death rates and overstate the long-run impact. Table 8 shows that this does not appear to be the case. Here, the gun buyback variable has been interacted with a dummy variable for each of three post-policy change year groupings (1997-1999, 2000-2002, and 20032006). In neither the case of firearm homicides nor firearm suicides is it 
Table 7. Estimated effects of firearms bought on death rates - allowing for linear trends, and a break in trend in 1988. Coefficients represent the impact of buying back 1000 firearms.

\begin{tabular}{|c|c|c|c|c|c|c|c|c|c|c|c|c|}
\hline \multirow[b]{2}{*}{ Suicide } & \multicolumn{4}{|l|}{ Firearm } & \multicolumn{4}{|c|}{ Non-firearm } & \multicolumn{4}{|l|}{ Total } \\
\hline & & & & & & & & & & & & \\
\hline Guns bought back & $\begin{array}{c}-0.296^{* * * *} \\
(5.09)\end{array}$ & $\begin{array}{c}-.0 .547^{* * *} \\
(4.56)\end{array}$ & $\begin{array}{c}-0.326^{* * * *} \\
(4.17)\end{array}$ & $\begin{array}{c}-0.543^{* *} \\
(3.66)\end{array}$ & $\begin{array}{c}0.702 \\
(1.01)\end{array}$ & $\begin{array}{c}0.424 \\
(0.75)\end{array}$ & $\begin{array}{c}0.554 \\
(1.57)\end{array}$ & $\begin{array}{c}0.150 \\
(0.90)\end{array}$ & $\begin{array}{l}0.407 \\
(0.61)\end{array}$ & $\begin{array}{r}-0.124 \\
(0.20)\end{array}$ & $\begin{array}{c}0.228 \\
(0.64)\end{array}$ & $\begin{array}{r}-0.394 \\
(1.41)\end{array}$ \\
\hline$R^{2}$ & 0.74 & 0.76 & 0.76 & 0.79 & 0.5 & 0.7 & 0.57 & 0.75 & 0.4 & 0.6 & 0.49 & 0.66 \\
\hline \multicolumn{13}{|l|}{ Homicide } \\
\hline Guns bought back & $\begin{array}{r}-0.138^{*} \\
(2.10)\end{array}$ & $\begin{array}{c}-0.227^{* * *} \\
(4.16)\end{array}$ & $\begin{array}{c}-0.139^{* *} \\
(2.18)\end{array}$ & $\begin{array}{r}-0.227^{*} \\
(2.38)\end{array}$ & $\begin{array}{r}-0.117 \\
(0.42)\end{array}$ & $\begin{array}{r}-0.099 \\
-0.35\end{array}$ & $\begin{array}{r}-0.051 \\
-0.29\end{array}$ & $\begin{array}{r}-0.031 \\
-0.17\end{array}$ & $\begin{array}{r}-0.255 \\
(0.74)\end{array}$ & $\begin{array}{r}-0.326 \\
(1.07)\end{array}$ & $\begin{array}{r}-0.189 \\
(0.84)\end{array}$ & $\begin{array}{r}-0.258^{*} \\
(2.01)\end{array}$ \\
\hline$R^{2}$ & 0.41 & 0.44 & 0.42 & 0.52 & 0.82 & 0.84 & 0.81 & 0.84 & 0.83 & 0.86 & 0.83 & 0.89 \\
\hline Year Fixed Effects & $\mathrm{y}$ & $\mathrm{y}$ & $\mathrm{y}$ & $\mathrm{y}$ & $\mathrm{y}$ & $\mathrm{y}$ & $\mathrm{y}$ & $\mathrm{y}$ & $\mathrm{y}$ & $\mathrm{y}$ & $\mathrm{y}$ & $\mathrm{y}$ \\
\hline State Fixed Effects & $\mathrm{y}$ & $\mathrm{y}$ & $\mathrm{y}$ & $\mathrm{y}$ & $\mathrm{y}$ & $\mathrm{y}$ & $\mathrm{y}$ & $\mathrm{y}$ & $\mathrm{y}$ & $\mathrm{y}$ & $\mathrm{y}$ & $\mathrm{y}$ \\
\hline State-specific Time Trends & & $\mathrm{y}$ & & $\mathrm{y}$ & & $\mathrm{y}$ & & $\mathrm{y}$ & & $\mathrm{y}$ & & $\mathrm{y}$ \\
\hline State-level socioeconomic controls & & & $\mathrm{y}$ & $\mathrm{y}$ & & & $\mathrm{y}$ & $\mathrm{y}$ & & & $\mathrm{y}$ & $\mathrm{y}$ \\
\hline
\end{tabular}

Note: Each cell is a separate regression, including state and year fixed effects. Death rates are deaths per million people. Gun buyback rate measured as guns per thousand people Robust $t-$ statistics in parentheses.

* significant at $10 \%$.

** significant at $5 \%$.

*** significant at $1 \%$ 
Table 8. Estimated effects of the gun buyback rate on death rates - incorporating dynamics (1968 to 2006). Guns coefficients represent the impact of buying back 1,000 firearms

\begin{tabular}{|c|c|c|c|c|c|c|c|c|c|c|c|c|}
\hline & \multicolumn{4}{|l|}{ Firearm } & \multicolumn{4}{|c|}{ Non-firearm } & \multicolumn{4}{|l|}{ Total } \\
\hline \multicolumn{13}{|l|}{ Suicide } \\
\hline \multicolumn{13}{|c|}{ Guns bought back interacted by years: } \\
\hline $1997-1999$ & $\begin{array}{c}-0.282^{* * * *} \\
(5.57)\end{array}$ & $\begin{array}{c}-0.493^{* * *} \\
(5.03)\end{array}$ & $\begin{array}{c}-0.369^{* * *} \\
(5.62)\end{array}$ & $\begin{array}{c}0.452^{* *} \\
(3.23)\end{array}$ & $\begin{array}{c}0.075 \\
(0.13)\end{array}$ & $\begin{array}{r}-0.034 \\
(0.07)\end{array}$ & $\begin{array}{r}-0.027 \\
(0.07)\end{array}$ & $\begin{array}{r}-0.263 \\
(1.01)\end{array}$ & $\begin{array}{r}-0.208 \\
(0.39)\end{array}$ & $\begin{array}{r}-0.526 \\
(0.93)\end{array}$ & $\begin{array}{r}-0.342 \\
(0.83)\end{array}$ & $\begin{array}{r}-0.715^{* *} \\
(1.88)\end{array}$ \\
\hline $2000-2002$ & $\begin{array}{c}-0329^{* * *} \\
(6.58)\end{array}$ & $\begin{array}{c}-0.580^{* * *} \\
(5.54)\end{array}$ & $\begin{array}{c}-0.424^{* * *} \\
(5.42)\end{array}$ & $\begin{array}{r}-0.505^{* *} \\
(2.86)\end{array}$ & $\begin{array}{c}0.658 \\
(0.77)\end{array}$ & $\begin{array}{c}0.547 \\
(0.72)\end{array}$ & $\begin{array}{c}0.583 \\
(0.98)\end{array}$ & $\begin{array}{r}0.201 \\
0.38\end{array}$ & $\begin{array}{c}0.329 \\
(0.40)\end{array}$ & $\begin{array}{r}-0.034 \\
(0.04)\end{array}$ & $\begin{array}{r}-0.158 \\
(0.25)\end{array}$ & $\begin{array}{l}-0.304 \\
(-0.46)\end{array}$ \\
\hline $2002-2006$ & $\begin{array}{c}-0.360^{* * *} \\
(3.32)\end{array}$ & $\begin{array}{c}-0.667^{* * *} \\
(9.81)\end{array}$ & $\begin{array}{c}-0.473^{* * *} \\
(5.54)\end{array}$ & $\begin{array}{c}0.579^{* * *} \\
(3.87)\end{array}$ & $\begin{array}{l}1.464^{*} \\
(2.22)\end{array}$ & $\begin{array}{c}1.327^{* * *} \\
(2.76)\end{array}$ & $\begin{array}{c}1.369^{* *} \\
(3.17)\end{array}$ & $\begin{array}{r}0.858^{* *} \\
(3.03)\end{array}$ & $\begin{array}{l}1.1 \\
(1.81)\end{array}$ & $\begin{array}{l}0.66 \\
(1.36)\end{array}$ & $\begin{array}{l}0.895^{*} \\
(2.15)\end{array}$ & $\begin{array}{c}0.279 \\
(0.76)\end{array}$ \\
\hline$R^{2}$ & 0.7312 & 0.7486 & 0.7753 & 0.7941 & 0.5221 & 0.7148 & 0.5917 & 0.7545 & 0.4262 & 0.6077 & 0.5145 & 0.6472 \\
\hline \multicolumn{13}{|l|}{ Homicide } \\
\hline \multicolumn{13}{|c|}{ Guns bought back interacted by years: } \\
\hline 1997-1999 & $\begin{array}{c}-0.076^{* *} \\
(2.42)\end{array}$ & $\begin{array}{c}-0.161^{* *} \\
(2.97)\end{array}$ & $\begin{array}{c}-0.111^{* *} \\
(2.39)\end{array}$ & $\begin{array}{r}-0.162 \\
(2.74)\end{array}$ & $\begin{array}{r}-0.256 \\
(0.61)\end{array}$ & $\begin{array}{r}-0.207 \\
(0.53)\end{array}$ & $\begin{array}{r}-0.233 \\
(0.64)\end{array}$ & $\begin{array}{r}-0.185 \\
(0.58)\end{array}$ & $\begin{array}{r}-0.332 \\
(0.76)\end{array}$ & $\begin{array}{r}-0.368 \\
(0.98)\end{array}$ & $\begin{array}{r}-0.344 \\
(0.93)\end{array}$ & $\begin{array}{r}-0.346 \\
(1.50)\end{array}$ \\
\hline
\end{tabular}


Table 8. (Continued)

\begin{tabular}{|c|c|c|c|c|c|c|c|c|c|c|c|c|}
\hline & Firearm & & & & Non-firea & & & & Total & & & \\
\hline $2000-2002$ & $\begin{array}{r}-0.118 \\
(1.31)\end{array}$ & $\begin{array}{c}-0.221^{* *} \\
(3.25)\end{array}$ & $\begin{array}{r}-0.148^{*} \\
(2.02)\end{array}$ & $\begin{array}{c}-0.199^{* *} \\
(2.74)\end{array}$ & $\begin{array}{r}-0.003 \\
(0.06)\end{array}$ & $\begin{array}{l}0.047 \\
(0.75)\end{array}$ & $\begin{array}{l}0.030 \\
(0.31)\end{array}$ & $\begin{array}{l}0.075 \\
(0.66)\end{array}$ & $\begin{array}{c}-0.121 \\
(0.88)\end{array}$ & $\begin{array}{r}-0.174^{*} \\
(2.02)\end{array}$ & $\begin{array}{r}-0.119 \\
(0.93)\end{array}$ & $\begin{array}{r}-0.124 \\
(0.80)\end{array}$ \\
\hline $2002-2006$ & -0.105 & $-0.231^{* * * *}$ & $-0.152^{* *}$ & $-0.213^{*}$ & -0.183 & -0.123 & -0.173 & -0.093 & -0.288 & -0.354 & -0.325 & $-0.306^{* *}$ \\
\hline$R^{2}$ & 0.4031 & 0.4392 & 0.4291 & 0.4979 & 0.8166 & 0.8422 & 0.8114 & 0.8466 & 0.8334 & 0.8653 & 0.8431 & 0.8926 \\
\hline Year Fixed Effects & $\mathrm{y}$ & $\mathrm{y}$ & $\mathrm{y}$ & $\mathrm{y}$ & $\mathrm{y}$ & $\mathrm{y}$ & $\mathrm{y}$ & $\mathrm{y}$ & $\mathrm{y}$ & $\mathrm{y}$ & $\mathrm{y}$ & $\mathrm{y}$ \\
\hline State Fixed Effects & $\mathrm{y}$ & $\mathrm{y}$ & $\mathrm{y}$ & $\mathrm{y}$ & $\mathrm{y}$ & $\mathrm{y}$ & $\mathrm{y}$ & $\mathrm{y}$ & $\mathrm{y}$ & $\mathrm{y}$ & $\mathrm{y}$ & $\mathrm{y}$ \\
\hline State-specific Time Trends & & $\mathrm{y}$ & & $\mathrm{y}$ & & $\mathrm{y}$ & & $\mathrm{y}$ & & $\mathrm{y}$ & & $\mathrm{y}$ \\
\hline Socio-economic controls & & & $\mathrm{y}$ & $\mathrm{y}$ & & & $\mathrm{y}$ & $\mathrm{y}$ & & & $\mathrm{y}$ & $\mathrm{y}$ \\
\hline Number of observations & 312 & 312 & 275 & 275 & 312 & 312 & 275 & 275 & 312 & 312 & 275 & 275 \\
\hline
\end{tabular}

Dependent variable is the identified death rate, in deaths per million people. Gun buyback rate is measured as guns per thousand people. Estimates from a panel model, with annual observations at the state level. Observations: 312 except for those using socio-economic controls which have 275. Robust $t$-statistics in parentheses.

* significant at $10 \%$

** significant at $5 \%$

*** significant at $1 \%$ level. 
possible to reject that the effect of the firearm buyback is equal across the three time periods.

There do appear to be some interesting dynamics in the case of nonfirearm suicides, however. The results suggest that states with larger firearm buybacks initially experienced a slight relative decline in nonfirearm suicides but then saw a large increase in non-firearm suicides in 2002-2006. Note that the bump-up in non-firearm suicides seen in the time series data (Figure 1a) in the 1996-1998 period is not easily attributable to method substitution or other factors associated with firearm withdrawals or other changes in firearm legislation that varied at the state level, since in that case we would expect to see states that had larger falls in firearm suicide also experience increases in non-firearm suicide. There is no empirical support for that in the data. The very late increase in non-firearm suicides in states with higher buyback rates is somewhat of a mystery. The magnitude of the later increase is two to five times the magnitude of the relative reduction in firearm suicides in the same period. Taken at face value as an indicator of method substitution, it would suggest that individuals only began substituting to other methods 6 years after the gun buyback and that the rate of substitution was greater than $100 \%$. It seems unlikely that this is consistent with any reasonable model of method substitution. It is possible that this reflects a change in the collection of suicide data post 2002 - that possibility is explored in Section 4.1.5.

\subsubsection{Examining sensitivity to the Port Arthur incident. Two other} important checks are excluding the deaths from Tasmania's Port Arthur massacre from the analysis and considering the possibility that the buyback had no effects on death rates until 1998. We do the first simply by including a dummy variable for Tasmania in 1996 and the second by dropping the year 1997 from the analysis. The results are shown in Table 9. As expected, including a dummy variable for Port Arthur only affects the magnitude of the estimates of firearm homicides. The point estimate falls by just under $40 \%$ in the model with no state-specific time trends, but by considerably more in the model including those trends. It appears that models incorporating state-specific time trends may particularly influence estimates of policy effects if either the initial or the final observations are unusually high or low. The inclusion of the Port Arthur dummy increases 
Table 9. Robustness of estimates of effect of the gun buyback rate on death rates to Port Arthur and dropping 1997 (1968 to 2006). Guns coefficients represent the impact of buying back 1,000 firearms

\begin{tabular}{|c|c|c|c|c|}
\hline & \multicolumn{2}{|l|}{ Firearm } & \multicolumn{2}{|c|}{ Non-firearm } \\
\hline & No trend & $\begin{array}{l}\text { Incl. state-specific } \\
\text { trend }\end{array}$ & No trend & $\begin{array}{l}\text { Incl. state-specific } \\
\text { trend }\end{array}$ \\
\hline \multicolumn{5}{|l|}{ Suicide } \\
\hline Basic & $\begin{array}{c}-0.327^{* * *} \\
(5.17)\end{array}$ & $\begin{array}{l}-0.569^{* * *} \\
(6.39)\end{array}$ & $\begin{array}{l}0.796 \\
(1.20)\end{array}$ & $\begin{array}{l}0.528 \\
(0.97)\end{array}$ \\
\hline$R^{2}$ & 0.7310 & 0.7476 & 0.4968 & 0.6915 \\
\hline Number of observations & 312 & 312 & 312 & 312 \\
\hline Port Arthur dummy & $\begin{array}{c}-0.338^{* * *} \\
(5.61)\end{array}$ & $\begin{array}{l}-0.650^{* * *} \\
(-5.22)\end{array}$ & $\begin{array}{c}0.799 \\
(1.20)\end{array}$ & $\begin{array}{l}0.546 \\
(0.97)\end{array}$ \\
\hline$R^{2}$ & 0.7344 & 0.7552 & 0.4969 & 0.6916 \\
\hline Number of observations & 312 & 312 & 312 & 312 \\
\hline Drop 1997 & $\begin{array}{c}-0.337^{* * *} \\
(4.63)\end{array}$ & $\begin{array}{l}-0.594^{* * *} \\
(7.82)\end{array}$ & $\begin{array}{l}0.930 \\
(1.40)\end{array}$ & $\begin{array}{l}0.707 \\
(1.31)\end{array}$ \\
\hline$R^{2}$ & 0.7282 & 0.7457 & 0.4987 & 0.6935 \\
\hline Number of observations & 304 & 304 & 304 & 304 \\
\hline \multicolumn{5}{|l|}{ Homicide } \\
\hline Basic & $\begin{array}{r}-0.100 \\
(1.57)\end{array}$ & $\begin{array}{l}-0.200^{* * * *} \\
(4.13)\end{array}$ & $\begin{array}{r}-0.150 \\
(0.54)\end{array}$ & $\begin{array}{l}-0.101 \\
(0.39)\end{array}$ \\
\hline$R^{2}$ & 0.4028 & 0.4382 & 0.8159 & 0.8415 \\
\hline Number of observations & 312 & 312 & 312 & 312 \\
\hline Port Arthur dummy & $\begin{array}{l}-0.062 \\
(-0.81)\end{array}$ & $\begin{array}{l}-0.018 \\
(0.20)\end{array}$ & $\begin{array}{r}-0.150 \\
(0.54)\end{array}$ & $\begin{array}{l}-0.110 \\
(0.40)\end{array}$ \\
\hline$R^{2}$ & 0.6197 & 0.6431 & 0.8159 & 0.8415 \\
\hline Number of observations & 312 & 312 & 312 & 312 \\
\hline Drop 1997 & $\begin{array}{r}-0.104 \\
(1.51)\end{array}$ & $\begin{array}{l}0.210^{* * * *} \\
(4.31)\end{array}$ & $\begin{array}{l}-0.150 \\
(-0.62)\end{array}$ & $\begin{array}{l}-0.097 \\
(0.46)\end{array}$ \\
\hline$R^{2}$ & 0.4018 & 0.4375 & 0.8263 & 0.8479 \\
\hline Number of observations & 304 & 304 & 304 & 304 \\
\hline
\end{tabular}

Dependent variable is the identified death rate, in deaths per million people. Gun buyback rate is measured as guns per thousand people. Estimates from a panel model, with annual observations at the state level. Observations: 312 except for those that drop 1997, which have 304. All specifications include state and year fixed effects, but not socio-economic controls. Robust $t$-statistics in parentheses.

* significant at $10 \%$.

** significant at $5 \%$.

$* * * \quad$ significant at $1 \%$ level.

the standard errors of the estimated effect of the buyback on firearm homicides enough that the estimated effect is now not statistically significantly different from zero, consistent with the "stripped down" model. The point estimate on firearm homicides in the model with no trends remains large relative to actual death rates, however-it suggests that the buyback of 3,500 guns per 100,000 individuals would lead to a 
decline in firearm homicide death rates of 0.22 per 100,000 , or about $50 \%$ of the 1990-95 average firearm homicide death rate. Excluding 1997 from the analysis has no important effect on the results. This is consistent with the finding that there are few dynamics in the effects of the buyback on death rates - firearm death rates appear to have fallen to a permanently lower level in relative terms around 1997 in states which had a relatively high buyback rate.

\subsubsection{Ensuring that estimated death rates post-1997 remain above}

zero. The use of the simple level specification has some drawbacks - in actuality, death rates are bounded at zero, and the use of the level specification allows for a non-zero probability to attach to negative death rates. That said, the only occasions on which there are negative in-sample predictions of death rates from these models are in several states' firearm homicide rates in the years 2004 and 2005, which have already been noted to have abnormally low firearm homicide (and overall homicide) rates. ${ }^{24}$ Nonetheless, it is desirable to estimate a model that does not allow this at all. Use of the log specification is not possible here because of the large number of observations where zero homicide deaths are recorded (both firearm and non-firearm). An alternative is to use the Tobit model, which allows for the fact that firearm deaths have a lower bound at zero. Estimates are shown for the homicides in Table $10 .^{25}$ The results indicate that the point estimates are robust to accounting for censoring at zero.

\subsubsection{Allowing for possible endogeneity of buyback rates. Above,} we discuss a number of potential ways in which the number of guns bought back in a state might be endogenous with respect to the future firearm death rate. ${ }^{26}$ While we regard each of these as unlikely, it is useful nonetheless to

24. This is largely due to the use of year fixed effects in the models; because of these year fixed effects, it is not possible to make out-of-sample predictions of death rates for Australia overall.

25. There is typically a sufficient number of suicides in every state that censoring is not a problem. As a result, Tobit estimates of the effect of the gun buyback on suicides are, like those for homicides, very similar to OLS estimates.

26. These include the possibility that a state's residents are able to forecast nonlinear trends in firearm death rates, and these forecasts affected their propensity to hand back their firearms under the NFA, or that the buyback rate in a state was affected by its exposure to the Port Arthur massacre, and the exposure also had a direct impact on subsequent firearm death rates. 
Table 10. Estimates of the effect of the gun buyback rate on homicide death rates: Tobit vs OLS (1968 to 2006). Guns coefficients represent the impact of buying back 1,000 firearms

\begin{tabular}{|c|c|c|c|c|c|c|}
\hline & \multicolumn{3}{|c|}{ Tobit estimates } & \multicolumn{3}{|c|}{ OLS estimates (no clustering) } \\
\hline & Firearm & Non-firearm & Total & Firearm & Non-firearm & Total \\
\hline \multicolumn{7}{|l|}{ No Port Arthur Dummy } \\
\hline $\begin{array}{l}\text { Guns bought back } \\
(t \text {-statistic) }\end{array}$ & $\begin{array}{r}-0.090 \\
(1.51)\end{array}$ & $\begin{array}{l}-0.195^{*} \\
(1.74)\end{array}$ & $\begin{array}{r}-0.263^{*} \\
(2.23)\end{array}$ & $\begin{array}{r}-0.100^{*} \\
(1.92)\end{array}$ & $\begin{array}{l}-0.150 \\
(1.26)\end{array}$ & $\begin{array}{r}-0.250^{* *} \\
(1.98)\end{array}$ \\
\hline$p$-value & 0.131 & 0.0083 & 0.027 & 0.056 & 0.207 & 0.049 \\
\hline Number censored: & 46 & 8 & 6 & & & \\
\hline Pseudo- $R^{2}$ & 0.0815 & 0.1730 & 0.1782 & 0.4028 & 0.8159 & 0.8330 \\
\hline \multicolumn{7}{|l|}{ Port Arthur Dummy } \\
\hline $\begin{array}{l}\text { Guns bought back } \\
\text { ( } t \text {-statistic) }\end{array}$ & $\begin{array}{r}-0.048 \\
(1.01)\end{array}$ & $\begin{array}{l}-0.195^{*} \\
(1.73)\end{array}$ & $\begin{array}{r}-0.224^{*} \\
(1.96)\end{array}$ & $\begin{array}{r}-0.062 \\
(1.48)\end{array}$ & $\begin{array}{l}-0.150 \\
(1.26)\end{array}$ & $\begin{array}{r}-0.212^{*} \\
(1.72)\end{array}$ \\
\hline$p$-value & 0.314 & 0.085 & 0.051 & 0.141 & 0.208 & 0.087 \\
\hline Number censored: & 46 & 7 & 4 & & & \\
\hline Pseudo- $R^{2}$ & 0.1378 & 0.1730 & 0.1843 & 0.6197 & 0.8159 & 0.8431 \\
\hline Number of observations & 312 & 312 & 312 & 312 & 312 & 312 \\
\hline
\end{tabular}

Dependent variable is the identified death rate, in deaths per million people. Gun buyback rate is measured as guns per thousand people. Estimates from a panel model, with annual observations at the state level. Observations: 312 except for those that drop 1997, which have 304. All specifications include state and year fixed effects, but not socio-economic controls. $t$-statistics in parentheses are not clustered at the state level, for comparability between Tobit and OLS estimates.

$*$ significant at $10 \%$.

$* *$ significant at $5 \%$.

*** significant at $1 \%$ level.

see whether our results are robust to instrumenting the state buyback rate. Allowing the possibility that the gun buyback rate may itself have varied with expectations of future changes in the state-level violent crime rate, we estimate instrumental variable models. To do this, we need an appropriate instrument - a variable that affects the buyback rate but is not correlated with firearms death rates after 1997 except through its impact on the buyback rate. We use cross-state differences in firearms ownership in the pre-buyback period as an instrument for the change in firearms ownership that occurred as a result of the buyback. This approach is akin to the use of existing immigrant stocks as an instrument for new immigrant inflows (see, e.g., Okkerse 2008). In such specifications, researchers exploit the fact that new immigrants tend to settle in places with large existing migrant stocks. This provides a means of identifying the exogenous "supply-push" effect of immigration on native wages. Similarly, we use the fact that some states have larger numbers of firearms in the pre-buyback period as a means of identifying differences in buyback rates after the NFA came into effect. 
We use the two proxies of gun ownership rates prior to 1997 shown in Table 3 as instruments. The percentage of all suicides that use firearms is not, however, a valid instrument for models of suicide rates, since it will clearly be correlated with the error term in the base regression-a positive shock to firearm suicides will clearly increase the proportion of suicides committed with a firearm. For firearm suicides, our instrument set is therefore the rate of gun ownership prior to 1996, estimated from the 1989 and 1992 ICVS surveys. For firearm homicides, we add the percentage of suicides that were completed using a firearm over the period 1994-1996 (using a 3-year average helps to reduce measurement error). The $F$ statistics on the first-stage regression range between 8 and 14, suggesting that our instruments have good predictive power. The results in Table 11 show that IV estimates of the effect of differences in the gun buyback rate on suicides are statistically indistinguishable from OLS estimates, and in particular, the IV estimates do not move in a positive direction relative to the OLS estimates. The IV results, then, provide further evidence that the findings of a statistically significant negative effect of the NFA on firearm homicides and suicides in the OLS estimates are not the result of a negative bias due to endogeneity of the buyback rate.

\subsubsection{Testing for inconsistencies in data collection for external} causes of death post-2002. As noted by the Australian Institute of Health and Welfare (AIHW 2009), there are some concerns that a change in the Australian Bureau of Statistics' method of collection of data on external causes of death after 2002 might have led to systemic underestimates of suicide deaths in particular. If this underestimation were consistent throughout Australia, then underestimates would not affect our results, since we include a full set of year fixed effects. However, if there were differences in under-reporting rates by state, and these happened to be correlated with the firearm buyback rate, our estimates might be biased. There is evidence that there were differences under-reporting by state. Interestingly, however, the AIHW report shows that Tasmania and the Northern Territory, which had the highest buyback rates, had almost no under-reporting, as did the Australian Capital Territory which had the lowest buyback rate (see Table 7). This would certainly not give much reason, then, to think that the results in this paper 
Table 11. (Continued)

\begin{tabular}{|c|c|c|c|c|c|c|c|c|c|c|c|c|}
\hline \multicolumn{4}{|c|}{ Basic models } & \multicolumn{9}{|c|}{ Including Port Arthur Dummy } \\
\hline $\begin{array}{l}\text { Guns bought } \\
t \text {-statistic }\end{array}$ & $\begin{array}{r}-0.122 \\
(1.36)\end{array}$ & $\begin{array}{c}-0.255^{* * *} \\
(3.49)\end{array}$ & $\begin{array}{r}-0.216 \\
(0.58)\end{array}$ & $\begin{array}{r}-0.156 \\
(0.46)\end{array}$ & $\begin{array}{r}-0.337 \\
(0.73)\end{array}$ & $\begin{array}{r}-0.411 \\
\quad(1.05)\end{array}$ & $\begin{array}{r}-0.077 \\
(0.76)\end{array}$ & $\begin{array}{l}-0.042 \\
(0.34)\end{array}$ & $\begin{array}{r}-0.217 \\
(0.57)\end{array}$ & $\begin{array}{r}-0.171 \\
(0.47)\end{array}$ & $\begin{array}{r}-0.293 \\
(0.61)\end{array}$ & $\begin{array}{r}-0.213 \\
(0.44)\end{array}$ \\
\hline \multicolumn{13}{|l|}{ Hausman test } \\
\hline $\begin{array}{l}\text { Difference } \\
t \text {-statistic }\end{array}$ & $\begin{array}{r}-0.022 \\
(0.34)\end{array}$ & $\begin{array}{c}-0.055 \\
(1.13)\end{array}$ & $\begin{array}{l}0.117 \\
(0.42)\end{array}$ & $\begin{array}{c}0.078 \\
(0.30)\end{array}$ & $\begin{array}{l}0.255 \\
(0.74)\end{array}$ & $\begin{array}{l}0.312 \\
(1.10)\end{array}$ & $\begin{array}{r}-0.015 \\
(0.20)\end{array}$ & $\begin{array}{c}-0.024 \\
(0.27)\end{array}$ & $\begin{array}{r}-0.067 \\
(0.24)\end{array}$ & $\begin{array}{r}-0.061 \\
(0.22)\end{array}$ & $\begin{array}{r}-0.081 \\
(0.23)\end{array}$ & $\begin{array}{r}-0.086 \\
(0.24)\end{array}$ \\
\hline$R^{2}$ & 0.4024 & 0.4371 & 0.8157 & 0.8415 & 0.8327 & 0.8647 & 0.6195 & 0.6429 & 0.8157 & 0.8415 & 0.8428 & 0.8347 \\
\hline Number of obs. & 312 & 312 & 312 & 312 & 312 & 312 & 312 & 312 & 312 & 312 & 312 & 312 \\
\hline \multicolumn{13}{|c|}{$\begin{array}{l}\text { Dependent variable is the identified death rate, in deaths per million people. Gun buyback rate is measured as guns per thousand people. Estimates from a panel model, with annual } \\
\text { observations at the state level. All specifications include state and year fixed effects, but not socio-economic controls. The panel to the right includes the Port Arthur dummy. Instruments } \\
\text { used are (a) the estimated rate of firearm ownership from the } 1989 \text { and } 1992 \text { ICVS surveys (figures provided in Table } 2 \text { ) and (b) the average percentage of suicides undertaken with a } \\
\text { firearm between } 1994 \text { and } 1996 \text {. (We assume that the firearm ownership rate in the ACT is the same as that in NSW.) Table } 3 \text { shows the first-stage regressions in the stripped down version } \\
\text { of the model. Results are similar for the panel model. Robust } t \text {-statistics in parentheses, clustered at the state level. } \\
* \text { significant at } 10 \% \text {. } \\
\begin{array}{ll}* * \\
* * *\end{array} \text { significant at } 5 \% \text {. } \\
\text { significant at } 1 \% \text { level. }\end{array}$} \\
\hline
\end{tabular}


would be biased downwards. Further, there appears to be little reason to think there is much mis-reporting in the data on firearm deaths. The AIHW report records very few cases in their audit of the data where firearm deaths were mis-coded.

Unlike other studies, our results are relatively insensitive to the particular time period chosen, and the results in Table 5, which show the dynamic effects of the NFA, show that the key estimates of reductions in firearm homicides and suicides are not an artifact of the years after 2002. Indeed, if anything, the only results that do appear to be affected by the post2002 years are those on non-firearm suicides, which show a larger increase in non-firearm suicide rates in states that had higher buyback rates. As discussed earlier, this is the most important reason for the overall positive point estimates of the effect of the NFA on non-firearm suicide rates. If this is a result of the change in data collection practices in 2002, then our results are if anything stronger.

Nonetheless, concerns about the effect of these data problems on our results may remain. Unfortunately, there is no plan to revise ABS estimates for death rates between 2002 and 2006, so we cannot expect significant improvements in these data in the future. We can, however, examine whether there is any evidence that a recoding of suicides to other external causes of death - in particular accidental deaths or deaths of undetermined intent - could have affected our results. We do this by simply running the same set of regressions for cases of accidental death and deaths of undetermined intent that we ran for homicides and suicides. If we find that the NFA appears to have led to an increase in either of these categories of death, we would be concerned that our results of a relatively large fall in firearm homicide and suicides in states with higher buyback rates represents a recategorization of deaths, rather than a decrease in actual deaths. In the case of firearm deaths, the small numbers of accidental deaths and deaths of undetermined intent mean that we are forced to group these together. They can be separated in the case of nonfirearm deaths, however. The estimates using Equation (1) show a very small negative and statistically insignificant ( $p$-value 0.344 ) effect of the buyback rate on deaths due to firearm accidents and deaths of undetermined intent. There is no reason to think, then, that the estimates on firearm homicides and suicides in particular are a result of misclassification of deaths. The results are the same for non-firearm deaths 
in those two categories, for all accidents, all deaths of undetermined intent, and for deaths due to ill-defined causes ( $p$-values $0.306,0.247,0.922$, and 0.594 , respectively). ${ }^{27}$

\section{Discussion and Conclusions}

In most developed countries, there are considerable restrictions on the availability of firearms, including outright bans on some types of firearms, licensing requirements which often require individuals to show a need for a firearm, and requirements for the registration of firearms. Evaluating the effectiveness of these regulations is extremely difficult. Australia's NFA provides a unique opportunity to examine the effects of a large-scale buyback of firearms on homicide and suicide.

With just under a decade of post-NFA deaths data now available, key studies based on time series data have agreed that there has been a significant fall in the number of firearm suicides in Australia since 1997. Firearm homicides also appear to have declined substantially, though with a smaller number of deaths per year, it is more difficult to be sure that this change was related to the NFA. At a minimum, there is some time series evidence against the notion that stricter gun laws have led to increases in total homicides.

The results in this paper-using a different and more reliable source of identification - support the general findings of those time series studies. We show that the largest falls in firearm deaths occurred in states where more firearms were bought back. Compared to time series studies, this approach has some key benefits. First, it allows us to control for national-level trends in death rates through the use of national-level fixed effects and at the state level through state-specific time trends - the results show that, even after controlling for such trends, there was a statistically significant decline in firearm deaths in states with higher firearm buyback rates. Second, we are able to examine in more depth the time pattern of any response of deaths to the NFA - the results show that firearm deaths in states with higher buyback rates fell relative to those with lower buyback rates and that this relative reduction in the firearm death rate was maintained subsequently. Finally, we use an instrumental variables strategy to allow

27. Full results are reported in Leigh and Neill (2010). 
for possible endogeneity in the gun buyback rate and find that this makes no substantive difference to the results. That the results in the baseline regression are robust to all three approaches suggests that the relationship between buyback rates and death rates is likely causal.

The estimated change in both firearm homicides and suicides is very large relative to their earlier averages, but confidence intervals on the estimated response of non-firearm homicides and suicides are large enough that it is not possible to rule out method substitution of a sufficient magnitude to offset the changes in firearm deaths. This is largely due to the fact that in Australia there are so many more nonfirearm suicides (and non-firearms homicides) than firearm deaths. ${ }^{28}$ However, two findings mitigate against the notion of substantial method substitution. First, non-firearm suicides and homicides fell substantially on aggregate in Australia in the period 1997-2006. Second, the estimated time pattern of the response of non-firearm deaths (suicides in particular) is not what we would expect to see in the case of method substitution. It is also inconsistent with suggestions, based on time series analysis, that the uptick in non-firearm suicides in the period 1997-2000 could have been a consequence of the buyback. Our results show, by contrast, that that jump occurred primarily in the states where the fewest guns were handed in, and where the gun buyback would have been expected to have the least effect.

For a firearm withdrawal equivalent to Australia's buyback, using quite conservative point estimates, our estimates suggest that over 200 firearm deaths per year-mostly suicides - would be averted in a population roughly the size of Australia's. The leading estimate of the value of a statistical life in Australia (Abelson 2003) is A $\$ 2.5$ million. ${ }^{29}$ If we

28. In Australia, firearms accounted for about one-fifth of all homicides and suicides in the mid-1990s (prior to the NFA) and about one-tenth of all homicides and suicides in the mid-2000s. In the United States, firearms account for about half of all suicides and two-thirds of all homicides, with the shares basically unchanged across this period.

29. Valuing homicide and suicide deaths at $\mathrm{A} \$ 2.5$ million may be an underestimate if the typical victim is aged less than 40 years of age (the benchmark age in Abelson's estimates) or if society's willingness to pay to avert a death is higher in the case of violent deaths. On the other hand, for cases of rational suicide, one might argue that a lower value should be placed on suicide deaths than on other deaths. Regardless, the figures here should be considered very rough indicators of the overall benefits of the NFA. 
assume that there was no offsetting increase in non-firearm deaths, the economic value of the gun buyback was $A \$ 500$ million per year or more than A $\$ 800$ per firearm bought back. This estimate is very sensitive to the assumptions, however, and in particular the assumption of no method substitution. The calculation also fails to account for any costs of more stringent firearms legislation.

There is a question as to whether it is reasonable to suggest that a withdrawal of about $20 \%$ of the stock of firearms could have plausibly led to drops of about $74 \%$ in the firearm suicide rate and perhaps $35-50 \%$ in firearm homicide rates. It should be noted that the standard errors on these estimates are fairly large, so that estimates of the declines in firearm homicide rates are usually not statistically significantly distinguishable from no effect. In the case of firearm suicides, however, the estimated $95 \%$ confidence intervals show that a buyback of 3,500 guns per 100,000 people would have reduced firearm suicides by a minimum percentage decline of $8 \%$. As we have noted above, the available data do not allow us to be sure as to whether the firearms withdrawn were relatively "high-risk" or "low-risk" firearms (i.e., whether they were more or less likely to have been used in homicides or suicides than firearms that were not withdrawn through the NFA). This is partly because firearm death data are not well disaggregated by the type of firearm but also because whether or not a firearm is "high risk" also depends on unobservable characteristics about its owner and other probable users.

A possible interpretation of the magnitude of our results is that the guns handed back were not low-risk firearms. The buyback focused mostly on automatic and semi-automatic long guns. In Australia, unlike some other countries, long guns have been the most common type of firearm used in both firearm homicides and firearm suicides, likely because handguns were already quite restricted well before the NFA. There are no data available on how important semi-automatic guns were in firearm deaths compared with other guns, however. While semi-automatic or automatic guns would be potentially more dangerous in the case of homicides, it is not clear that this would also apply to suicides.

Perhaps a more likely explanation of the strength of the relationship found is that the NFA led states with relatively weak legislation or enforcement relating to sale, ownership, and storage of firearms to strengthen their regimes relative to states with initially stronger 
standards. There is evidence that states with relatively high firearm ownership and therefore high gun buyback rates also had relatively weak regulation prior to 1996. Then, our estimates need to be interpreted as reflecting a combination of both the removal of firearms and the relative strengthening of legislation and enforcement. We might expect to see smaller effects in the case of a buyback that was not accompanied by stricter firearm legislation.

Several factors are important in assessing the extent to which the results from the Australian buyback can be extrapolated to other countries. Australian borders are more easily controlled than in countries that have land borders. In addition, Australia's government in general and its policing and customs services in particular are highly organized and effective. The NFA also had an extremely high degree of political support and was quite competently executed. And the buyback was accompanied by a uniform national system for licensing and registration of firearms. These factors should be borne in mind in considering the extent to which the results from the Australian NFA might generalize to other countries.

\section{References}

Abelson, Peter. 2003. "The Value of Life and Health for Public Policy," 79 Economic Record S2-13.

Ajdacic-Gross, Vladeta, Martin Killias, Urs Hepp, Erika Gadola, Matthias Bopp, Christoph Lauber, Ulrich Schnyder, Felix Gutzwiller, and Wulf Rössler. 2006. "A Longitudinal Analysis of International Firearm Suicide Data," 96 American Journal of Public Health 1752-5.

Australian Institute of Health and Welfare (AIHW) Harrison, J.E., S. Pointer, and A. A. Elnour. 2009. "A Review of Suicide Statistics in Australia," Injury Research and Statistics Series. no. 49 Cat. no. INJCAT 121. Adelaide: AIHW.

Baker, Jeanine, and Samara McPhedran. 2007. "Gun Laws and Sudden Death: Did the Australian Firearms Legislation of 1996 Make a Difference?" 47 British Journal of Criminology 455-69.

Bertrand, Marianne, Esther Duflo, and Sendhil Mullainathan. 2004. "How Much Should We Trust Differences-in-Differences Estimates?” 119 Quarterly Journal of Economics 249-75.

Bridges, F.S., and J.C. Kunselman. 2004. "Gun Availability and Use of Guns for Suicide, Homicide and Murder in Canada," 98 Perceptual and Motor Skills 594-7. 
Callahan, Charles M., Frederick P. Rivara, and Thomas D. Koepsell. 1994. "Money for Guns: Evaluation of the Seattle Gun Buy-Back Program," 109 Public Health Reports 472-7.

Carpenter, Christopher. 2004. "Heavy Alcohol Use and Youth Suicide: Evidence from Tougher Drunk Driving Laws," 23 Journal of Policy Analysis and Management 831-42.

Carrington, Peter J. 1999. "Gender, Gun Control, Suicide and Homicide in Canada," 5 Archives of Suicide Research 71-5.

Cebula, Richard J., and Tatyana V. Zelenskaya. 2006. "Determinants of Youth Suicide: A Friendly Comment with Suggestions," 65 The American Journal of Economics and Sociology 991-6.

Chapman, S., Phillip Alpers, K. Agho, and M. Jones. 2006. “Australia's 1996 Gun Law Reforms: Faster Fall in Firearm Deaths, Firearm Suicides and a Decade Without Mass Shootings," 12 Injury Prevention 365-72.

Cook, Philip J., and Jens Ludwig. 2006. "The Social Costs of Gun Ownership,” 90 Journal of Public Economics 379-91.

Duggan, Mark. 2001. "More Guns, More Crime," 109 Journal of Political Economy 1086-114.

Fishback, Price V., Michael R. Haines, and Shawn Kantor. 2007. "Births, Deaths, and New Deal Relief During the Great Depression," 89 The Review of Economics and Statistics $1-14$.

Gruber, Jonathan. 2004. "Is Making Divorce Easier Bad for Children? The LongRun Implications of Unilateral Divorce," 22 Journal of Labor Economics 799-834.

Hamermesh, Daniel S., and Neal M. Soss. 1974. "An Economic Theory of Suicide," 82 The Journal of Political Economy 83-98.

Harding, Richard W. 1981. Firearms and Violence in Australian Life: An Examination of Gun Ownership and Use in Australia. Nedlands, WA: University of Western Australia Press.

Kleck, Gary. 2001. "Impossible Policy Evaluation and Impossible Conclusions-A Comment on Koper and Roth," 17 Journal of Quantitative Criminology 75-80.

Koper, Christopher S., and Jeffrey A. Roth. 2001a. "The Impact of the 1994 Federal Assault Weapon Ban on Gun Violence Outcomes: An Assessment of Multiple Outcome Measures and Some Lessons for Policy Evaluation," Journal of Quantitative Criminology 33-74.

___ 2001b. "A Priori Assertions Versus Empirical Inquiry: A Reply to Kleck," 17 Journal of Quantitative Criminology 81-8.

Killias, Martin. 1993. "International Correlations Between Gun Ownership and Rates of Homicide and Suicide," 148 Canadian Medical Association Journal 1721-5.

Lee, Wang-Sheng, and Sandy Suardi. 2010. "The Australian Firearms Buyback and Its Effect on Gun Deaths,” 28 Contemporary Economic Policy 65-79. 
Leenaars, Antoon A., and David Lester. 1996. "Gender and the Impact of Gun Control on Suicide and Homicide," 2 Archives of Suicide Research 223-34.

Leigh, Andrew, and Christine Neill. 2010. "Do Gun Buybacks Save Lives? Evidence from Panel Data," IZA Discussion Paper 4995. IZA: Bonn.

Levitt, Steven D. 2004. "Understanding Why Crime Fell in the 1990s: Four Factors That Explain the Decline and Six That Do Not," 18 Journal of Economic Perspectives 163-90.

Ludwig, Jens, and Philip J. Cook. 2000. "Homicide and Suicide Rates Associated With Implementation of the Brady Handgun Violence Prevention Act," 284 Journal of the American Medical Association 585-91.

Marceau, Nicolas. 1998. "Self-Selection and Violence in the Market for Crime," 17 International Review of Law and Economics 193-201.

Miller, M., D. Azrael, L. Hepburn, D. Hemenway, and S.J. Lippmann. 2005. "The Association Between Changes in Household Firearm Ownership and Rates of Suicide in the United States, 1981-2002," 12 Injury Prevention 178-82.

Narayan, Paresh Kumar, and Russell Smyth. 2004. "Crime Rates, Male Youth Unemployment and Real Income in Australia: Evidence from Granger Causality Tests," 36 Applied Economics 2079-95.

Neill, Christine, and Andrew Leigh. 2008. "Do Gun Buybacks Save Lives? Evidence from Time Series Variation," 20 Current Issues in Criminal Justice 145-62.

Neumayer, Eric. 2003. "Socioeconomic Factors and Suicide Rates at Large-Unit Aggregate Levels: A Comment," 40 Urban Studies 2769-76.

Okkerse, Liesbet. 2008. "How to Measure Labour Market Effects of Immigration: A Review," 22 Journal of Economic Surveys 1-30.

Ozanne-Smith, J., K. Ashby, S. Newstead, V.Z. Stathakis, and A. Clapperton. 2004. "Firearm Related Deaths: The Impact of Regulatory Reform," 10 Injury Prevention 280-6.

Reuter, Peter and Jenny Mouzos. 2003. “Australia: A Massive Buyback of Low-Risk Guns" in Jens Ludwig and Philip J. Cook, eds., Evaluating Gun Policy: Effects on Crime and Violence. Washington, DC: Brookings Institute Press.

Rosenfeld, R. 1995. "Gun Buybacks: Crime Control or Community Mobilization" in Martha R. Plotkin, ed., Under Fire: Gun Buy-Backs, Exchanges and Amnesty Programs. Washington DC: Police Executive Research Forum.

Rosengart, M., P. Cummings, A. Nathens, P. Heagerty, R. Maier, and F. Rivara. 2007. "An Evaluation of State Firearm Regulations and Homicide and Suicide Death Rates," 11 Injury Prevention 77-83.

Small Arms Survey Geneva. Small Arms Survey 2007: Guns and the City. Cambridge: Cambridge University Press.

Stevenson, Betsey, and Justin Wolfers. 2006. "Bargaining in the Shadow of the Law: Divorce Laws and Family Distress," 121 Quarterly Journal of Economics 267-88. 
Do Gun Buybacks Save Lives? Evidence from Panel Data 557

Varen, Matti. 2004. "Suicide and Business Cycles: New Empirical Evidence," 12 Applied Economics Letters 887-891.

Wolfers, Justin. 2006. "Did Unilateral Divorce Laws Raise Divorce Rates? A Reconciliation and New Results," 96 American Economic Review 1802-20. 